\title{
Vapor pressures of substituted polycarboxylic acids are much lower than previously reported
}

\author{
A. J. Huisman ${ }^{1, *}$, U. K. Krieger ${ }^{1}$, A. Zuend ${ }^{2,{ }^{* *}}$, C. Marcolli ${ }^{1}$, and T. Peter ${ }^{1}$ \\ ${ }^{1}$ Institute for Atmospheric and Climate Science, ETH Zurich, 8092 Zurich, Switzerland \\ ${ }^{2}$ Department of Chemical Engineering, California Institute of Technology, Pasadena, California 91125, USA \\ *now at: Chemistry Department, Union College, Schenectady, New York 12308, USA \\ ** now at: Institute for Atmospheric and Climate Science, ETH Zurich, 8092 Zurich, Switzerland
}

Correspondence to: A. J. Huisman (huismana@union.edu) and U. K. Krieger (ulrich.krieger@env.ethz.ch)

Received: 30 November 2012 - Published in Atmos. Chem. Phys. Discuss.: 10 January 2013

Revised: 4 June 2013 - Accepted: 7 June 2013 - Published: 12 July 2013

\begin{abstract}
The partitioning of compounds between the aerosol and gas phase is a primary focus in the study of the formation and fate of secondary organic aerosol. We present measurements of the vapor pressure of 2-methylmalonic (isosuccinic) acid, 2-hydroxymalonic (tartronic) acid, 2methylglutaric acid, 3-hydroxy-3-carboxy-glutaric (citric) acid and DL-2,3-dihydroxysuccinic (DL-tartaric) acid, which were obtained from the evaporation rate of supersaturated liquid particles levitated in an electrodynamic balance. Our measurements indicate that the pure component liquid vapor pressures at $298.15 \mathrm{~K}$ for tartronic, citric and tartaric acids are much lower than the same quantity that was derived from solid state measurements in the only other room temperature measurement of these materials (made by Booth et al., 2010). This strongly suggests that empirical correction terms in a recent vapor pressure estimation model to account for the inexplicably high vapor pressures of these and similar compounds should be revisited, and that due caution should be used when the estimated vapor pressures of these and similar compounds are used as inputs for other studies.
\end{abstract}

\section{Introduction}

The production of secondary organic aerosol (SOA) by gasto-particle partitioning is generally represented by an equilibrium partitioning model such as that of Pankow (1994, 2003). This framework has recently been applied in box models and large scale atmospheric models by means of a volatility basis set (VBS; see, e.g., Donahue et al., 2011, and ref- erences therein). A key physical parameter which governs gas-particle partitioning is the pure component vapor pressure $\left(p^{\circ}\right)$, which is difficult to accurately measure at atmospheric temperatures for low- and semi-volatile organic compounds (L/SVOC) such as polycarboxylic acids. Note that throughout this article, the term "vapor pressure" is used as defined by chemical thermodynamics to denote the partial pressure of a compound in equilibrium with a liquid or solid phase, which is sometimes emphasized by the equivalent term "equilibrium vapor pressure".

Vapor pressure measurements of L/SVOC may be made by following the volatilization of bulk samples (e.g., Verevkin et al., 2000; Ribeiro da Silva et al., 2001; Booth et al., 2010; Bruns et al., 2012), ensembles of airborne or deposited droplets (e.g., Cappa et al., 2007; Salo et al., 2010), and single trapped airborne droplets (e.g., Zardini et al., 2006; Pope et al., 2010; Soonsin et al., 2010; Krieger et al., 2012) or by other techniques such as gas-liquid chromatography (see review by Letcher and Naicker, 2004). Generally, the agreement of different techniques is reasonable for measurements in which the sample state is positively identified and unexpectedly poor for measurements where the physical state is not well controlled (Soonsin et al., 2010; M. Bilde, personal communication, 2012). Vapor pressures are generally reported for the liquid state $p^{\circ, \mathrm{L}}$ (not to be confused with $p^{\circ}$, which we will use to denote the vapor pressure of a pure compound in an unspecified physical state), which is the reference state for most models of atmospheric partitioning. However, vapor pressure measurements of polyacids are generally made in the solid state $\left(p^{\circ, \mathrm{S}}\right)$ as these compounds have 
a melting point above room temperature. The measured solid state vapor pressure $p^{\circ, \mathrm{S}}$ can be converted to the liquid vapor pressure $p^{\circ, \mathrm{L}}$ by the enthalpy of fusion, the melting temperature, and the change in heat capacity upon melting (Prausnitz et al., 1999). While it is possible to measure either $p^{\circ, \mathrm{S}}$ or $p^{\circ, \mathrm{L}}$, it is preferable to measure directly in the liquid state when reporting $p^{\circ, \mathrm{L}}$ to circumvent the phase conversion and its associated uncertainty. As these compounds are solid at room temperature, measurements of $p^{\circ, \mathrm{L}}$ can only be made directly in small droplets, in which strong supersaturations or subcoolings can be maintained without crystallization.

There are several cases (e.g., tartaric compared with succinic acid) in which the $p^{\circ, \mathrm{L}}$ reported by Booth et al. (2010) increases upon functionalization of the carbon backbone with an oxygen-bearing substituent, a counterintuitive result. There have been a few specific cases reported in the literature where addition of an oxygen-bearing functional group to a parent structure can lead to an increase of the solidstate vapor pressure. As discussed in Zuend and Seinfeld (2012), such effects have been reported, e.g., by Chattopadhyay and Ziemann (2005) for substitutions where a ketone group is added in $\alpha$-position to a carboxyl group. While keto substitutions in $\alpha$-position of a carboxyl group can raise the solid-state vapor pressure of a dicarboxylic acid with respect to the unsubstituted parent structure, keto substitutions at a $\beta$-position or further away from the carboxyl group always resulted in decreased solid-state vapor pressure. Chattopadhyay and Ziemann (2005) suggest that a ketone group in $\alpha$ position may form an internal hydrogen bond with the carboxyl group. Such an internal hydrogen bond may reduce the level of intermolecular hydrogen bonding and may lead to an increase in vapor pressure relative to the unsubstituted parent carboxylic acid. However, such effects on the pure compound vapor pressure have been observed only for samples measured in the solid state. Although the presence of intermolecular group interactions may lessen the reduction in vapor pressure as compared to the prediction of a simple "additive" group-contribution model, the typical behavior observed is that addition of an oxygen-bearing functional group to an organic structure lowers the pure compound vapor pressure. In this study, we present $p^{\circ, \mathrm{L}}$ measured using an electrodynamic balance (EDB) to directly access supersaturated liquid-state conditions in single droplets of five compounds, including three of the functionalized polycarboxylic acids for which Booth et al. (2010) reported unexpected high volatility. To the authors' knowledge, these are the first measurements of $p^{\circ, \mathrm{L}}$ obtained directly from the liquid state for 2-hydroxymalonic acid (2-hMA), 2-methylglutaric acid (2mGA), and tartaric acid (TA).

The number of different compounds present in atmospheric aerosols necessitates the use of estimation methods that rely on structure-activity relationships, such as the Nannoolal et al. (2008) or Moller et al. (2008) methods or EVAPORATION (Estimation of VApour Pressure of ORganics, Accounting for Temperature, Intramolecular, and Non- additivity effects) (Compernolle et al., 2011) to estimate the aerosol mass generated by chemical processing of volatile and semivolatile organic compounds in the gas and particle phases. In this study, we focus on comparison of our measurements to the EVAPORATION model, which is intended to enable the prediction of $p^{\circ, \mathrm{L}}$ for polyfunctional molecules that occur in SOA. The model has been optimized to account for the influence of hydrogen bonding and intramolecular group interactions on $p^{\circ, \mathrm{L}}$ and has been parameterized with the most recent experimental data for polyfunctional acids. Although Compernolle et al. (2011) endeavor to reproduce measurements of $p^{\circ, \mathrm{L}}$ for substituted polyacids reported by Booth et al. (2010) by implementing an empirical correction term, they are not able to rationalize these effects. Because only few measurements are available for such compounds, a danger of overfitting exists (see discussion in Barley and McFiggans, 2010), especially since some compounds have been measured only with a single technique. This highlights the need for accurate measurements of $p^{\circ}$ (and especially direct measurements of $p^{\circ, \mathrm{L}}$ ) to assure the accuracy of models of partitioning-driven aerosol formation. In their manuscript, Compernolle et al. (2011) noted that measurements using the methodology of Soonsin et al. (2010) were needed for these compounds. The measurements presented in this work begin to address that need, but are not intended to be an exhaustive set that will allow for a re-fitting of models such as EVAPORATION. Rather, we intend them to demonstrate the existence of substantial deviations from previous experimental data and as an immediate caveat to anyone using EVAPORATION or similar models to predict partitioning of substituted polycarboxylic acids. Finally, we show that the EVAPORATION model can be modified to yield predictions in better agreement with our measurements.

\section{Method}

Vapor pressures of pure melts and aqueous solutions of substituted polycarboxylic acids were measured using the electrodynamic balance (EDB) apparatus and technique described in Soonsin et al. (2010). In this technique, the evaporation rate of a levitated particle is related to vapor pressure via continuum theory (see discussion in Sect. IV of Krieger et al., 2012). The EDB apparatus consists of a threewall temperature-controlled glass chamber containing a levitated charged particle held in place through applied electric $\mathrm{AC}$ and DC fields. A constant flow (typically $25 \mathrm{sccm}$ ) of a $\mathrm{N}_{2} / \mathrm{H}_{2} \mathrm{O}$ gas mixture with a controlled $\mathrm{H}_{2} \mathrm{O}$ partial pressure is pumped continuously through the chamber at a constant total pressure adjustable between 200 and $1000 \mathrm{hPa}$. The temperature can be varied between $330 \mathrm{~K}$ and $160 \mathrm{~K}$ with a stability better than $0.1 \mathrm{~K}$ and an accuracy of $\pm 0.5 \mathrm{~K}$. The relative humidity in the chamber is set by automatic mass flow controllers regulating the $\mathrm{N}_{2} / \mathrm{H}_{2} \mathrm{O}$ mixing ratio. During an experiment, the temperature and the relative humidity 
are kept constant while measuring a particular evaporation rate. Note that the $\mathrm{N}_{2} / \mathrm{H}_{2} \mathrm{O}$ gas flow is completely free of any evaporated organic molecules prior to entering the glass chamber as the gas flow is freshly generated from a purified liquid $\mathrm{N}_{2}$ reservoir, part of which is flowing over an enclosed temperature-controlled liquid solution of purified, deionized water containing $2.5 \mathrm{wt}-\%$ of dissolved sulfuric acid to scrub any ammonia from laboratory air potentially leaking into the system. Injection solutions had an analyte content between $0.5 \%$ and $4 \%$ by weight, leading to particles of approximately 2 to $9 \mu \mathrm{m}$ dry radius. Evaporation of the solvent from the particle was judged to be complete when a steady shrink rate was established under constant temperature ( $T$ ) and relative humidity (RH). Highly supersaturated particles with respect to solid phases can be obtained due to the small (micrometer-range) particle radius and wall-free containment of the EDB. For simplicity, we will refer to measurements as being on a "solution" without specifying if the sample was supersaturated, or on the "subcooled melt" for the pure component. All measurements were taken on spherically symmetric (i.e., non-crystalline) particles, as judged by the regularity of the angular fringes of scattered laser light (see Zardini et al., 2006), and measurements were made on at least two particles for all investigated substances.

Throughout each measurement, $T, \mathrm{RH}$, and background gas pressure were held constant (to within $0.25 \mathrm{~K}, 0.5 \%$, and 1 torr, respectively), and the particle radius was measured to a high degree of precision using morphology (radius) dependent resonance spectrometry (Zardini et al., 2006). Vapor pressure measurements were made on subcooled melt droplets or solution droplets with the organic concentration in water controlled by the RH in the EDB. A continuous flow of $20-35 \mathrm{~cm}^{3} \mathrm{~min}^{-1}$ organic-free $\mathrm{N}_{2}$ gas with a known water content was applied and the ambient pressure was regulated to $600 \pm 1$ torr $(79.99 \pm 0.13 \mathrm{kPa})$. As the partial pressure of the organic decreases with decreasing organic solute activity on the mole fraction basis $\left(a_{\text {org }}\right)$, measurements were most often performed at low to moderate humidity ( $\mathrm{RH}<40 \%$ ).

After the particle was equilibrated with respect to $T$ and $\mathrm{RH}$, any change in size was attributed to evaporative loss (cf., Sect IV of Krieger et al., 2012), and the vapor pressure ( $p$ ) of the organic substance under those conditions (RH, $T$ ) was calculated using Eq. (1) of Soonsin et al. (2010):

$p=-\frac{1}{2} \frac{\mathrm{d} r^{2}}{\mathrm{~d} t} \times \frac{x \rho R T}{\left(x M_{\mathrm{org}}+(1-x) M_{\mathrm{w}}\right) D_{\mathrm{v}}}$.

where $r$ is the particle radius, $x$ is the mole fraction of the organic solute, $\rho$ is the density of the condensed phase, $R$ is the gas constant, $M$ is molar mass, $D_{\mathrm{v}}$ is the diffusivity of the organic vapor in the buffer atmosphere, and "org" and "w" refer to the organic component and water, respectively. Strictly, Eq. (1) is valid for stagnant conditions. However, the geometry of our EDB together with the flows used keeps the enhancement in evaporation rate due to the gas flow below
$0.1 \%$ (Zhang and Davis, 1987). On the other hand, the flow needs to be sufficiently large to avoid any significant contamination of the gas phase by the organic vapor evaporating from the particle. The partial pressure of the organic substance far from the particle, $p_{\infty}$, has to be only a small fraction of the vapor pressure $p$. Our flows are sufficient to keep the ratio $p_{\infty} / p$ below $1 \%$, (cf., Zhang and Davis, 1987). The derivation or measurement of each term in Eq. (1) will be discussed below.

\subsection{Radius}

The particle radius as a function of time was determined by combining an absolute radius from the two-dimensional scattering pattern at one point in time with the fractional change in particle radius as a function of time from morphology dependent resonance spectroscopy (Zardini et al., 2006):

$r(t)=r\left(t_{0}\right) \times \frac{\lambda(t)}{\lambda\left(t_{0}\right)}$,

where $t_{0}$ is the initial time and $\lambda$ is the wavelength at which the Mie resonance occurs. Each particle was sized at one stage of the experiment, and the radius was calculated at all other times based on that initial radius and the change in radius calculated from Mie spectra, such that the retrieved radius of the particle was self-consistent. In this calculation of particle radius, we have neglected any shift in Mie peaks arising from changes in the index of refraction due to changing RH. Examples of raw radius data as a function of time at constant $T$ and RH are given for 2-mGA, CA, and TA in Appendix A and shown in Fig. A1.

The absolute radius of the particle at one point in time was retrieved from the spacing of fringes of the two-dimensional scattering pattern at $90^{\circ}$ following the method outlined in Eq. (25) of Glantschnig and Chen (1981). Using the small angle approximation, we equate the angular separation of fringes $\Delta \theta$ with their linear separation on the detector. Calibration was performed by injecting a single latex sphere (Polyscience Inc., Warrington, PA, nominal diameter $10 \mu \mathrm{m}$ ) and measuring the separation of the fringes.

The fractional change in particle radius was measured by tracking the change in wavelength of a Mie scattering resonance from a single particle as a function of time $\left(\frac{\mathrm{d} \lambda}{\mathrm{d} t}\right)$. As in Zardini et al. (2006), the particle was illuminated with a LED $\left(\lambda_{\text {center }}=589 \mathrm{~nm}, \mathrm{FWHM}=16 \mathrm{~nm}\right.$, radiant power $\left.150 \mu \mathrm{W}\right)$ and backscattered light was collected and imaged using a $150 \mathrm{~mm}$ spectrograph with a CCD detector. The quantity $\frac{\mathrm{d} \lambda}{\mathrm{d} t}$ is directly related to the change in size of a particle when following a single Mie resonance (Zardini et al., 2006), if the index of refraction of the particle is constant. The change in wavelength of a group of Mie resonances as a function of time, $\frac{\mathrm{d} \lambda}{\mathrm{d} t}$, was retrieved using a custom script based on a digital image correlation algorithm in the Mathworks Matlab environment. This quantity was then used along with the retrieved $r\left(t_{0}\right)$ to calculate $r(t)$ via Eq. (2). 


\subsection{Mole fraction of solute}

The mole fraction of organic compound in an aqueous particle was calculated from the RH in the EDB by assuming that the particle $a_{\mathrm{w}}$ is equivalent to measured RH, i.e., that the particle is homogeneous and in thermodynamic equilibrium. The thermodynamic group-contribution model AIOMFAC (Aerosol Inorganic-Organic Mixtures Functional groups Activity Coefficients) developed by Zuend et al. (2008, 2011) was used to calculate activity coefficients of water and organic compounds as a function of the droplet mixture composition. The activity coefficients account for non-ideal mixing, which influences vapor pressure via modified Raoult's law (Zuend et al., 2010). For simplicity, AIOMFAC was run at $298.15 \mathrm{~K}$ and used at all $T$; the model output varies by less than $1 \%$ between $298.15 \mathrm{~K}$ and $313 \mathrm{~K}$ (the highest temperature used).

\subsection{Density}

Density was parameterized by assuming additivity of the molar volumes of the components and fitting experimental data to the equation

$\rho=\frac{x \times M_{\text {org }}+(1-x) \times M_{\mathrm{w}}}{x \times V_{\text {org }}+(1-x) \times V_{\mathrm{w}}}$,

where $V$ is the molar volume, and all other variables and subscripts are defined as above. Such a fit is necessary because density measurements are available only for (sub-)saturated bulk solutions, while measurements often took place under highly supersaturated conditions. The molar volumes of 2hMA and 2-mMA were retrieved from the SciFinder website, which provides $V_{\text {org }}$ calculated by the Advanced Chemistry Development, Inc. software (ACD/Labs, 2012). Measurements of 2-mGA density were made using a $10 \mathrm{~mL}$ pycnometer (Blaubrand, 43408) on solutions from 0.11 to 0.75 weight fraction organic in water. We determined $V_{\text {org }}$ of $119.7 \pm 0.3 \mathrm{~cm}^{3} \mathrm{~mol}^{-1}$ for 2 -mGA by fitting $V_{\text {org }}$ to experimentally determined densities of aqueous solutions using Eq. (3). Experimental data from Laguerie et al. (1976) and Washburn et al. (1926) were used to calculate the molar volume of CA and TA, respectively. All density parameters used in this study are summarized in Table 1 and the raw data for 2-mGA density as a function of solute weight fraction in water are given in Table 2 .

\subsection{Diffusivity of organic vapor}

The diffusivity of organic vapor in nitrogen was estimated following the method of Bilde et al. (2003): the group contribution method of Lydersen (1955) was used to determine the critical volume $V_{\mathrm{c}}$ and the diffusivities used in this study were calculated using Eqs. (17.3-12) from Bird et al. (2007):

$D_{\mathrm{v}}=0.0018583 \times \sqrt{T^{3} \times\left(\frac{1}{M_{\mathrm{N}_{2}}}+\frac{1}{M_{\text {org }}}\right)} \times \frac{1}{P \times \sigma_{\mathrm{AB}}^{2} \times \Omega}$,
Table 1. Partial molar volumes of compounds under study. The "Quality $R^{2}$ " column refers to the correlation coefficient of a fit of Eq. (3) using the stated $V_{\text {org }}$ to experimental data.

\begin{tabular}{lll}
\hline Material & Quality $R^{2}$ & $V_{\text {org }}\left(\mathrm{cm}^{3} \mathrm{~mol}^{-1}\right)$ \\
\hline 2-Methylmalonic acid & N/A & $84 \pm 3$ \\
2-Hydroxymalonic acid & N/A & $65 \pm 3$ \\
2-Methylglutaric acid & 0.9981 & $119.7 \pm 0.3$ \\
Citric acid & 0.9981 & $118.9 \pm 0.3$ \\
DL-tartaric acid & 0.997 & $85.8 \pm 0.3$ \\
\hline
\end{tabular}

Table 2. Density of 2-methylglutaric acid solutions in water. All measurements carry an error of $1.5 \times 10^{-3} \mathrm{~g} \mathrm{~cm}^{-3}$.

\begin{tabular}{lc}
\hline $\begin{array}{l}\text { Solute weight } \\
\text { fraction }\end{array}$ & $\begin{array}{c}\text { Density } \\
\left(\mathrm{g} \mathrm{cm}^{-3}\right)\end{array}$ \\
\hline 0.1080 & 1.0182 \\
0.2020 & 1.0369 \\
0.2934 & 1.0587 \\
0.3971 & 1.0811 \\
0.5296 & 1.1037 \\
0.7502 & 1.1555 \\
\hline
\end{tabular}

where $P$ is the ambient gas pressure, $\sigma_{\mathrm{AB}}$ is one of the Lennard-Jones parameters for the organic material in $\mathrm{N}_{2}, \Omega$ is the collisional integral, and all other symbols are defined as above. The values of $D_{\mathrm{v}}$ for each material are given for $T=298.15 \mathrm{~K}$ in Table 3 .

\subsection{Materials}

Materials were as follows: Millipore water (resistivity > $18.2 \mathrm{M} \Omega \mathrm{cm}$, total organic content $<5 \mathrm{ppb}$ ) was used as the injection solvent for 2-methylmalonic acid (2-mMA, 2-methylpropanedioic acid, Sigma-Aldrich >99\%), 2hydroxymalonic acid (2-hMA, 2-hydroxypropanedioic acid, $>97 \%$, Sigma-Aldrich), 2-methylglutaric acid (2-mGA, 2methylpentanedioic acid, >99\% ABCR, Karlsruhe, Germany and $>98 \%$, Fluka), and citric acid monohydrate (CA, 3-carboxy-3-hydroxypentanedioic acid, Fluka, >99.5\%). A mixture of approximately $1: 1$ by volume diethylene glycol (Fluka, $>99 \%$ ) with Millipore water was used as an injection solvent for DL-tartaric acid (TA, 2,3dihydroxybutanedioic acid, $>99 \%$, Aldrich) to prevent crystallization upon injection that occurs when pure water is used. All reagents were used as received with no additional purification. Organic-free, very low humidity nitrogen carrier gas was obtained from the blowoff of a dewar containing liquid nitrogen. 
Table 3. Parameters for estimation of organic compound vapor diffusivity in $\mathrm{N}_{2}$ at 600 torr $(\sim 80 \mathrm{kPa})$ at $298.15 \mathrm{~K}$.

\begin{tabular}{lrrrrr}
\hline Material & $\begin{array}{r}V_{\mathrm{c}} \\
\mathrm{cm}^{3}\end{array}$ & $\begin{array}{r}\sigma_{\mathrm{B}} \\
\AA\end{array}$ & $\begin{array}{r}\epsilon_{\mathrm{AB}} / k_{\mathrm{B}} \\
\mathrm{K}\end{array}$ & $\Omega$ & $\begin{array}{r}D_{\mathrm{V}} \\
\mathrm{cm}^{2} \mathrm{~s}^{-1}\end{array}$ \\
\hline 2-Methylmalonic acid & 306 & 4.667 & 279.7 & 1.40 & 0.0835 \\
2-Hydroxymalonic acid & 269 & 4.548 & 287.4 & 1.42 & 0.0867 \\
2-Methylglutaric acid & 380 & 6.091 & 260.1 & 1.347 & 0.0777 \\
Citric acid & 449 & 6.440 & 285.8 & 1.406 & 0.0681 \\
DL-Tartaric acid & 338 & 5.858 & 291.6 & 1.440 & 0.0762 \\
\hline
\end{tabular}

\section{Analysis}

\subsection{Extraction of $p^{\circ, \mathrm{L}}$ as a function of temperature}

While $p^{\circ, \mathrm{L}}$ is the quantity of interest in this study, higher quality data are achieved by measuring $p^{\mathrm{L}}$ of aqueous solutions of the organic compound at several concentrations to extract $p^{\circ, \mathrm{L}}$ at $a_{\text {org }}=1$. When measurements of $p^{\mathrm{L}}$ were available at multiple $a_{\text {org }}$, a weighted linear least-squares fit of the data through $\left(a_{\mathrm{org}}=0, p=0 \mathrm{~Pa}\right)$ was used to extract $p^{\circ, \mathrm{L}}$. The data in Fig. 1 are an example of the retrieved $p^{\mathrm{L}}$ of 2-mGA as a function of $a_{\text {org }}$ at a single $T$. The error of the resulting fit slope was propagated from the calculated error on each point following the method of Lyons (1986, p. 127) and used in the calculation of the error on $p^{\circ, \mathrm{L}}$ at each $T$; in general, points with longer duration measurement or at lower water activity $\left(a_{\mathrm{w}}\right)$ have smaller error bars. As discussed in Soonsin et al. (2010), the linear fit of $p^{\mathrm{L}}$ against $a_{\text {org }}$ provides a more robust measure of $p^{\circ, \mathrm{L}}$ than a single measurement at $a_{\text {org }}=1$.

As the materials under study here have lower $p^{\circ, \mathrm{L}}$ than those in the preceding study by Soonsin et al. (2010), which employed the same EDB apparatus, it was not always possible to quantify the evaporative loss of particle mass. Therefore, a detailed error analysis was performed that allows us to report an upper limit for measurements below the limit of quantitation (LoQ, see, e.g., Armbruster and Pry, 2008, for a discussion on the difference between limit of detection and $\mathrm{LoQ}$ ). A detailed treatment of error on the measurement shown in Fig. 1 is given in Appendix B. Conservatively, we assume that a size change of $1 \mathrm{~nm}$ on a $10 \mu \mathrm{m}$ particle is needed to accurately quantify the change in radius, leading to a LoQ of $3.6 \times 10^{-7} \mathrm{~Pa}$ for a $24 \mathrm{~h}$ measurement, and neglecting any confounding effects from instrumental noise or drift (which will become increasingly important for multiday experiments). In general, the statistical (propagated) error upon which we base our stated uncertainties is around a factor of 2 higher than the theoretical LoQ, primarily due to the influence of minor drifts in RH (cf., Appendix B2) on the statistical error.

Measurements with calculated uncertainties that extend to negative pressure are considered indistinguishable from zero; in such a case only an upper bound on $p^{\mathrm{L}}$ is reported and

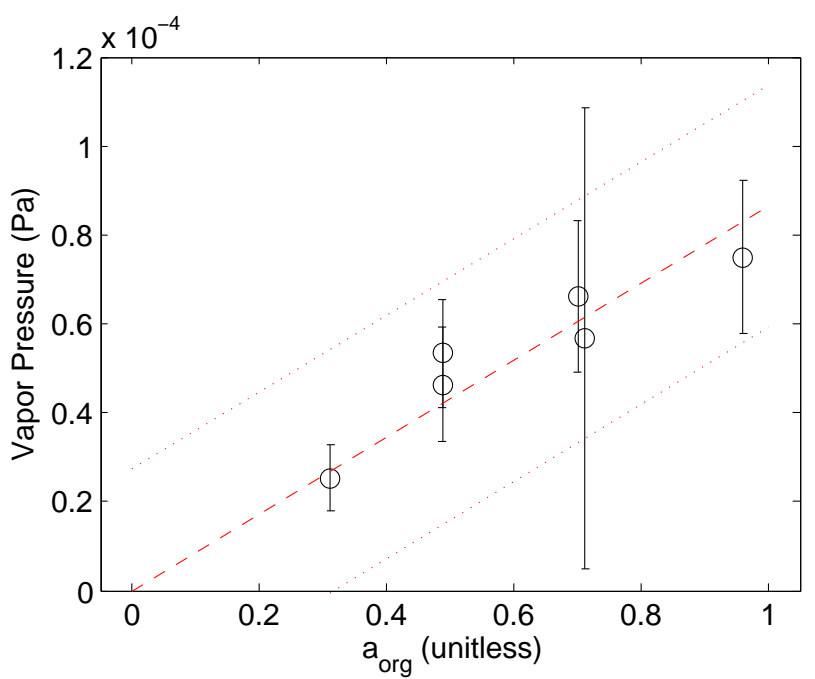

Fig. 1. Measured vapor pressure $p^{\mathrm{L}}$ of 2-methylglutaric acid (circles) as a function of the mole fraction based organic activity $a_{\text {org }}$ at $280.5 \mathrm{~K}$. The value of the (dashed) fit line intercept at $a_{\mathrm{org}}=1 \mathrm{rep}-$ resents the pure component liquid vapor pressure at $280.5 \mathrm{~K}$ and $2 \sigma$ error bounds are shown by dotted lines. The fit line is made through the origin and data are weighted by the square of their inverse relative error. For the calculation of error bounds and a more complete description of the error analysis, see Appendix B.

that point is excluded from the fit for $p^{\circ, \mathrm{L}}$. In the event that all measurements at a given $T$ were indistinguishable from zero, the upper bound of $p^{\circ, \mathrm{L}}$ at that $T$ was calculated as $\min \left(\boldsymbol{p}_{\text {upper }} / \boldsymbol{a}_{\text {org }}\right)$, where $\boldsymbol{p}_{\text {upper }}$ and $\boldsymbol{a}_{\text {org }}$ are the upper limits of the measured $p^{\mathrm{L}}$ and organic activities corresponding to the compositions at the points, respectively, and the / sign indicates element-wise division. Using this quantity rather than the simple upper-limit pressure takes into account the decrease in $p^{\mathrm{L}}$ for a solution compared to the pure liquid.

\subsection{Extraction of $p^{\circ, \mathrm{L}}\left(T^{\ominus}\right)$}

The pure component liquid vapor pressures $p^{\circ, \mathrm{L}}$ derived in Sect. 3.1 are fit and displayed as a function of $\frac{1}{T}$ using the Clausius-Clapeyron equation:

$\ln \left(\frac{p^{\circ, \mathrm{L}}(T)}{p^{\circ, \mathrm{L}}\left(T^{\ominus}\right)}\right)=\frac{-\Delta H_{\mathrm{vap}}^{\ominus}}{R}\left(\frac{1}{T}-\frac{1}{T^{\ominus}}\right)$

where $\Delta H_{\text {vap }}^{\ominus}$ is the enthalpy of vaporization of the organic component at $T^{\ominus}$ and the superscript ${ }^{\ominus}$ indicates the standard state with $T^{\ominus}=298.15 \mathrm{~K}$. This formula assumes that the enthalpy of vaporization $\Delta H_{\text {vap }}^{\ominus}$ is constant over the range of $T$ used in measurements $(\sim 30 \mathrm{~K})$. The fit line to Eq. (5) was weighted by the inverse square of the relative error on each point to extract $p^{\circ, \mathrm{L}}\left(T^{\ominus}\right)$ and the statistical error was propagated using the method of Lyons (1986, p. 126-127). 
Table 4. Vapor pressure data from this study and comparison to data from the literature. Abbreviations are: 2-mMA, 2-methylmalonic acid; 2-hmA, 2-hydroxymalonic acid; 2-mGA, 2-methylgluratic acid; 3-mGA, 3-methylglutaric acid; TA, DL-tartaric acid; CA, citric acid. Data are organized as experimental studies reporting liquid-state vapor pressure $\left(p^{\circ, \mathrm{L}}\right)$, experimental studies reporting solid-state vapor pressure $\left(p^{\circ, \mathrm{S}}\right)$, and model predictions of liquid-state vapor pressure $\left(p^{\circ, \mathrm{L}}\right)$, including 3-methylglutaric acid for comparison to 2-methylglutaric acid. All data are reported in $\mathrm{Pa}$ at $T^{\ominus}=298.15 \mathrm{~K}$ unless stated otherwise. For citric and tartaric acids, extrapolations to $T^{\ominus}$ are reported along with data obtained at $T>T^{\ominus}$. Superscript letters indicate notes on data or reference.

\begin{tabular}{|c|c|c|c|c|c|c|}
\hline & 2-mMA & 2-hMA & 2-mGA & 3-mGA & TA & $\mathrm{CA}$ \\
\hline \multicolumn{7}{|c|}{ Experimental liquid-state measurements } \\
\hline This Measurement & $(1.1 \pm 0.3) \times 10^{-3}$ & $(4.4 \pm 1.2) \times 10^{-6}$ & $(1.0 \pm 0.2) \times 10^{-3}$ & - & $(3.2 \pm 1.0) \times 10^{-7}(\sim 305 \mathrm{~K})$ & $<1.6 \times 10^{-7}(\sim 311 \mathrm{~K})$ \\
\hline This Measurement $^{\mathrm{a}}$ & - & - & - & - & $(8.6-24) \times 10^{-8}$ & $<4.0 \times 10^{-8}$ \\
\hline This Measurement ${ }^{b}$ & - & - & - & - & $(1.8-4.9) \times 10^{-8}$ & $<1.4 \times 10^{-9}$ \\
\hline Booth et al. (2010) & $(5.3 \pm 4.0) \times 10^{-3}$ & $(5.6 \pm 4.2) \times 10^{-3}$ & $(9.6 \pm 7.2) \times 10^{-4}$ & $(9.2 \pm 6.9) \times 10^{-4}$ & $(3.2 \pm 2.4) \times 10^{-1}$ & $(3.1 \pm 2.3) \times 10^{-3}$ \\
\hline Mønster et al. (2004) ${ }^{\mathrm{c}}$ & $(9.1 \pm 3.2) \times 10^{-4}$ & - & - & $(7.3 \pm 2.6) \times 10^{-4}$ & - & - \\
\hline Yaws et al. $(2009)^{\mathrm{d}}$ & - & - & - & - & - & $(1-40) \times 10^{-9}$ \\
\hline \multicolumn{7}{|c|}{ Experimental solid-state measurements } \\
\hline Booth et al. (2010) & $(3.3 \pm 1.3) \times 10^{-4}$ & $(2.5 \pm 1.0) \times 10^{-4}$ & $(1.9 \pm 0.7) \times 10^{-4}$ & $(1.8 \pm 0.7) \times 10^{-4}$ & $(1.8 \pm 0.7) \times 10^{-4}$ & $(3.8 \pm 1.5) \times 10^{-5}$ \\
\hline Ribeiro da Silva et al. $(2000)^{\mathrm{e}}$ & $(5.8 \pm 2.9) \times 10^{-4}$ & - & - & - & - & - \\
\hline Ribeiro da Silva et al. $(2001)^{\mathrm{f}}$ & - & - & $2.3_{-1.2}^{+2.6} \times 10^{-4}$ & - & - & - \\
\hline de Wit et al. (1983) ${ }^{\mathrm{g}}$ & - & - & - & - & $(1.3-2.6) \times 10^{-9}$ & - \\
\hline \multicolumn{7}{|l|}{ Model liquid-state predictions } \\
\hline Compernolle et al. $(2011)^{\mathrm{h}}$ & $\left(5.0_{-3.0}^{+7.7}\right) \times 10^{-3}$ & $\left(1.9_{-0.5}^{+0.6}\right) \times 10^{-3}$ & $\left(5.4_{-3.2}^{+8.1}\right) \times 10^{-4}$ & - & $\left(4.0_{-2.4}^{+6.1}\right) \times 10^{-3}$ & $\left(5.0_{-3.0}^{+7.7}\right) \times 10^{-5}$ \\
\hline Compernolle et al. $(2011)^{\mathrm{i}}$ & $\left(5.0_{-3.0}^{+7.7}\right) \times 10^{-3}$ & $\left(9.1_{-5.5}^{+14}\right) \times 10^{-5}$ & $\left(5.4_{-3.2}^{+8.1}\right) \times 10^{-4}$ & - & $\left(2.8_{-1.7}^{+4.2}\right) \times 10^{-7}$ & $\left(8.7_{-5.2}^{+13.1}\right) \times 10^{-10}$ \\
\hline Nannoolal et al. $(2008)^{\mathrm{j}}$ & $(3.7 \pm 3.1) \times 10^{-2}$ & $(2.0 \pm 1.7) \times 10^{-6}$ & $(3.1 \pm 2.7) \times 10^{-3}$ & - & $(1.4 \pm 1.2) \times 10^{-9}$ & $(9.1 \pm 7.8) \times 10^{-13}$ \\
\hline Moller et al. $(2008)^{\mathrm{k}}$ & $(1.1 \pm 0.3) \times 10^{-1}$ & $(2.1 \pm 0.5) \times 10^{-4}$ & $(8.2 \pm 2.0) \times 10^{-3}$ & - & $(6.9 \pm 1.7) \times 10^{-8}$ & $(2.7 \pm 0.6) \times 10^{-10}$ \\
\hline
\end{tabular}

a Extrapolation to $T^{\ominus}$ using $\Delta H_{\mathrm{vap}}=75 \mathrm{~kJ} \mathrm{~mol}^{-1}$.

${ }^{\mathrm{b}}$ Extrapolation to $T^{\ominus}$ using $\Delta H_{\mathrm{vap}}=250 \mathrm{~kJ} \mathrm{~mol}^{-1}$.

c Assumed liquid (the physical state was not specified), see Sect. 4.1.

${ }^{\mathrm{d}}$ Extrapolation of data from $426 \mathrm{~K}<T<451 \mathrm{~K}$.

e Extrapolation of data from $341 \mathrm{~K}<T<354 \mathrm{~K}$.

${ }^{\mathrm{f}}$ Extrapolation of data from $338 \mathrm{~K}<T<348 \mathrm{~K}$.

g Extrapolation of sublimation data from $411 \mathrm{~K}<T<440 \mathrm{~K}$

${ }^{\mathrm{h}}$ EVAPORATION model.

${ }^{\mathrm{i}}$ EVAPORATION model without correction for substituted polycarboxylic acids.

$\mathrm{j}$ The method of Nannoolal et al. (2008) was used with the $T_{\mathrm{b}}$ estimate of Nannoolal et al. (2004).

${ }^{\mathrm{k}}$ The method of Moller et al. (2008) was used with the $T_{\mathrm{b}}$ estimate of Nannoolal et al. (2004).

\section{Results and discussion}

The $p^{\circ, \mathrm{L}}$ determined here, along with a comparison to previous measurements in both the liquid $\left(p^{\circ, \mathrm{L}}\right)$ and solid states $\left(p^{\circ, \mathrm{S}}\right)$ and to a few common models of vapor pressure, are summarized in Table 4 and graphically depicted in Fig. 2. Figures 3 through 7 show the pure compound vapor pressure $p^{\circ, \mathrm{L}}$ obtained in this study as a function of inverse temperature (cf., Eq. 5) for each compound. Experimental data are shown as open symbols with error bounds extending to two standard errors; within each plot, different particles are shown using different symbols. The dashed fit line in these figures is made by weighting the data by the square of their inverse relative error, and extends to $T^{\ominus}=298.15 \mathrm{~K}$. The $2 \sigma$ bounds of fit lines are shown as dotted lines. Data that are indistinguishable from zero are reported as the highest value allowed by the statistical (propagated) error, and displayed in plots with their bottom error bar off-scale.

\subsection{2-Methylmalonic acid}

The $p^{\circ, \mathrm{L}}$ of 2-mMA as a function of inverse $T$ is displayed in Fig. 3. Based on the fit of Eq. (5) to these data, we determine $\Delta H_{\text {vap }}^{\ominus}=(89 \pm 15) \mathrm{kJ} \mathrm{mol}^{-1}$. Measurement times shown were a few hours to a few days per point, not including instrument settling time. The calculated $p^{\circ, \mathrm{L}}\left(T^{\ominus}\right)$ of $(1.1 \pm 0.3) \times 10^{-3} \mathrm{~Pa}$ is just inside the lower error bound of the measurements of Booth et al. (2010) and is in excellent agreement with the measurement of Mønster et al. (2004) for this compound.

Although the physical state of the aerosol was not reported in the study of Mønster et al. (2004), we assert that it was liquid as our measurements of 2-mMA carried out under dry $(\mathrm{RH}<3 \%)$ conditions for many days did not result in particle crystallization. Measurements in the tandem differential mobility analyzer (TDMA) used by Mønster et al. (2004) were performed on a shorter timescale and used aerosol particles of smaller size than our measurement, both of which decrease the probability of crystallization. This assertion is supported by Riipinen et al. (2007), who determined that 


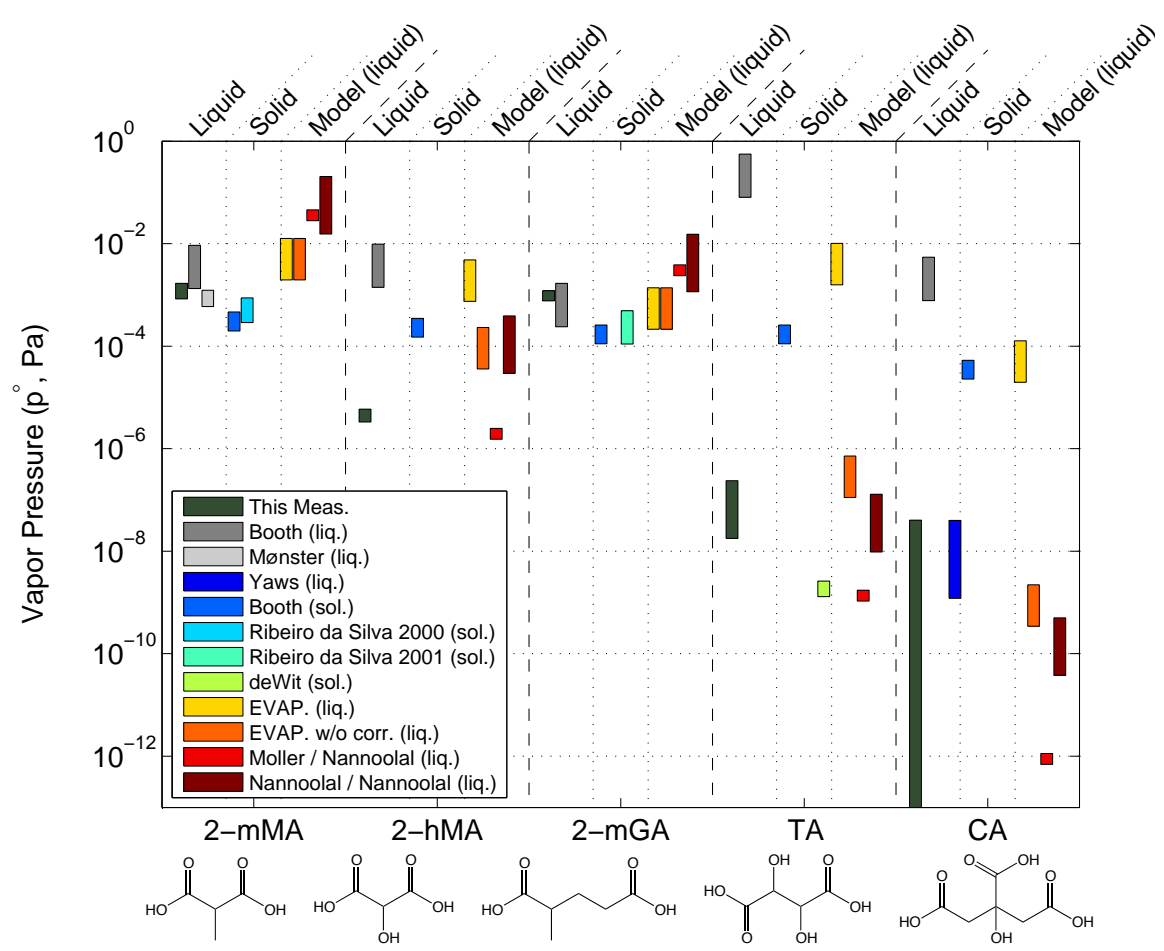

Fig. 2. Pure component vapor pressures at $T=298.15\left(p^{\circ}\left(T^{\ominus}\right)\right)$ for 2-methylmalonic acid (2-mMA), 2-hydroxymalonic acid (2-hMA), 2methylglutaric acid (2-mGA), DL-tartaric acid (TA), and citric acid (CA) - from this work (liquid) and from previous measurements reported in the liquid state, the solid state and the EVAPORATION model with and without empirical correction term as well as two commonly used models (all in liquid state). CA from this study is shown using the most conservative (largest) upper limit. Counter intuitively, the liquid vapor pressure measured here for 2-hMA, TA and CA is smaller than the solid-state vapor pressure reported by Booth et al. (2010). See Table 4 for full reference list.

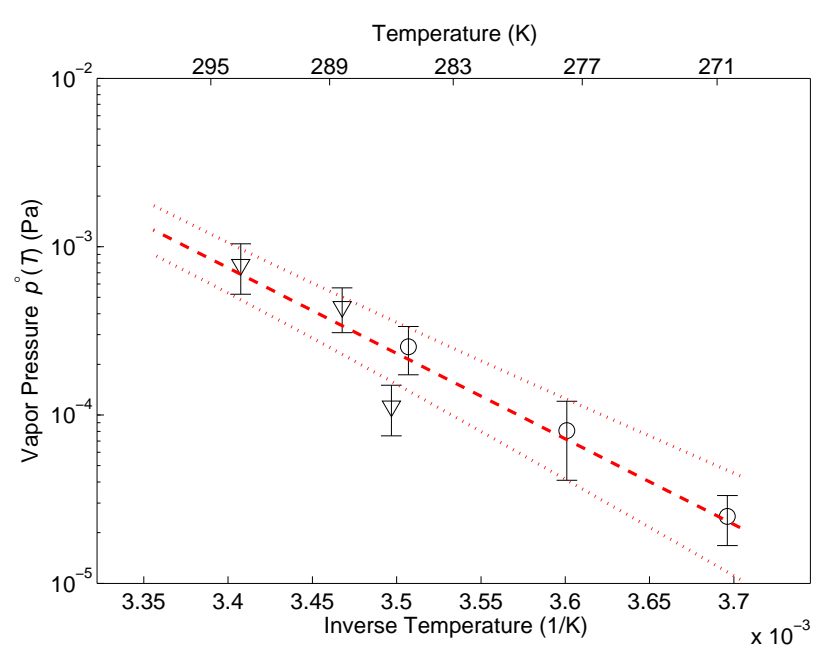

Fig. 3. Pure component vapor pressure $p^{\circ, \mathrm{L}}$ of 2-methylmalonic acid (open symbols, denoting two different particles). Fit line (dashed) is to Eq. (5) with $2 \sigma$ error bounds shown as dotted lines. malonic acid was in the liquid state during vapor pressure measurements, employing the same technique and apparatus as that of Mønster et al. (2004).

\subsection{2-Hydroxymalonic acid}

The $p^{\circ, \mathrm{L}}$ of 2-hMA is displayed in Fig. 4 using the same axes and fitting procedure as for 2-mMA in Sect. 4.1. We determine $\Delta H_{\text {vap }}^{\ominus}=(120 \pm 19) \mathrm{kJ} \mathrm{mol}^{-1}$ from a fit of Eq. (5) to experimental data. Measurement times shown were many hours to a few days per point, not including instrument settling time. The calculated $p^{\circ, \mathrm{L}}\left(T^{\ominus}\right)$ of $(4.4 \pm 1.2) \times 10^{-6} \mathrm{~Pa}$ is around three orders of magnitude lower than the value of $p^{\circ, \mathrm{L}}$ reported by Booth et al. (2010).

\subsection{2-Methylglutaric acid}

The $p^{\circ, \mathrm{L}}$ of 2-mGA is displayed in Fig. 5 using the same axes and fitting procedure as for 2-mMA in Sect. 4.1. We determine $\Delta H_{\text {vap }}^{\ominus}=(97.3 \pm 3.5) \mathrm{kJ} \mathrm{mol}^{-1}$ by fitting Eq. (5) to the experimental data. Measurement times shown in Fig. 5 were a few hours to several days per point, not including instrument settling time. These data demonstrate that the EDB method is reliable over a broad range of pressures and can 


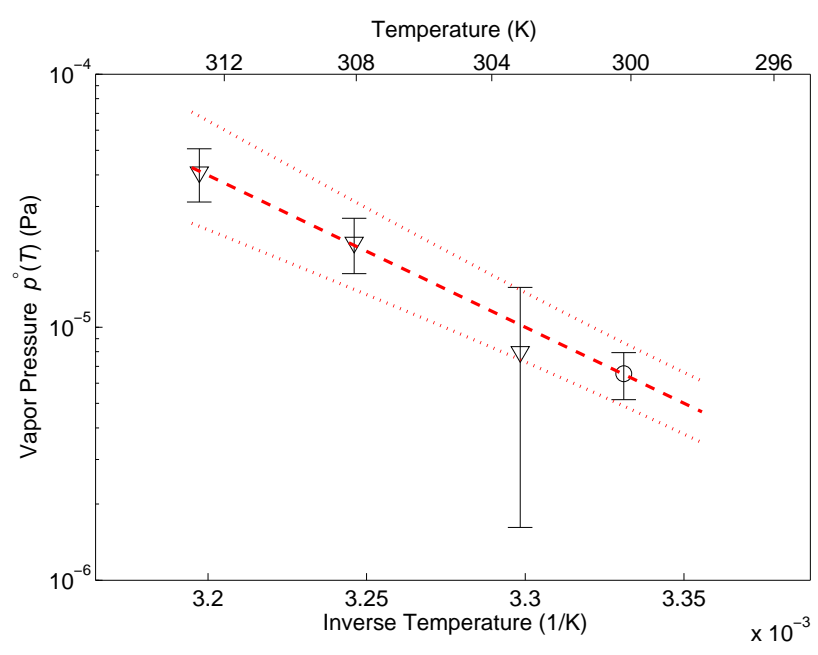

Fig. 4. Pure component vapor pressure $p^{\circ, \mathrm{L}}$ of 2-hydroxymalonic acid (open symbols, denoting two different particles). Fit line (dashed) is to Eq. (5) with $2 \sigma$ error bounds shown as dotted lines.

retrieve pressures of $1 \times 10^{-6} \mathrm{~Pa}$ and lower. The calculated $p^{\circ, \mathrm{L}}\left(T^{\ominus}\right)$ of $(1.0 \pm 0.2) \times 10^{-3} \mathrm{~Pa}$ agrees very well with the value reported by Booth et al. (2010).

We also compare our results to previous measurements of 3-methylglutaric acid (a structural isomer of 2-mGA that is expected to have a similar $\left.p^{\circ, \mathrm{L}}\right)$. Our measurements of 2mGA are in very good agreement with the $p^{\circ, \mathrm{L}}\left(T^{\ominus}\right)$ for 3methylglutaric acid reported by Booth et al. (2010) and by Mønster et al. (2004). As in Sect. 4.1, we assume that the measurements of Mønster et al. (2004) represent the liquid state. Once again, measurements of 2-mGA were made under very dry $(\mathrm{RH}<3 \%)$ conditions and no crystallization of the particle was observed.

\subsection{Tartaric acid}

Two measurements of DL-tartaric Acid (TA) $p^{\circ, \mathrm{L}}$ are shown in Fig. 6. Measurement times were 2 days $(312 \mathrm{~K})$ and 11 days $(305.5 \mathrm{~K})$, not including instrument settling time. As only one point was distinguishable from zero, a fit to determine $\Delta H_{\text {vap }}^{\ominus}$ is not possible, so we extrapolate to $T^{\ominus}$ using Eq. (5) and two values of $\Delta H_{\text {vap }}^{\ominus}$, which should cover the range of possibilities: 75 and $250 \mathrm{~kJ} \mathrm{~mol}^{-1}$ (cf., Fig. 2 of Compernolle et al., 2011). Using $\Delta H_{\text {vap }}^{\ominus}=75 \mathrm{~kJ} \mathrm{~mol}^{-1}, p^{\circ, \mathrm{L}}$ is calculated to be in the range $(8.6-24) \times 10^{-8} \mathrm{~Pa}$, while $\Delta H_{\text {vap }}^{\ominus}=250 \mathrm{~kJ} \mathrm{~mol}^{-1}$ yields a $p^{\circ, \mathrm{L}}$ of $(1.8-4.9) \times 10^{-8}$ $\mathrm{Pa}$. This result is approximately six orders of magnitude lower than the measurement of Booth et al. (2010). We note that tartaric acid has several stereoisomers and can be purchased as D-, L-, DL-, and meso-tartaric acid. The measurement of Booth et al. (2010) was also performed on the DLstereoisomer (A. M. Booth, personal communication, 2013), so the results of this study should be strictly comparable to

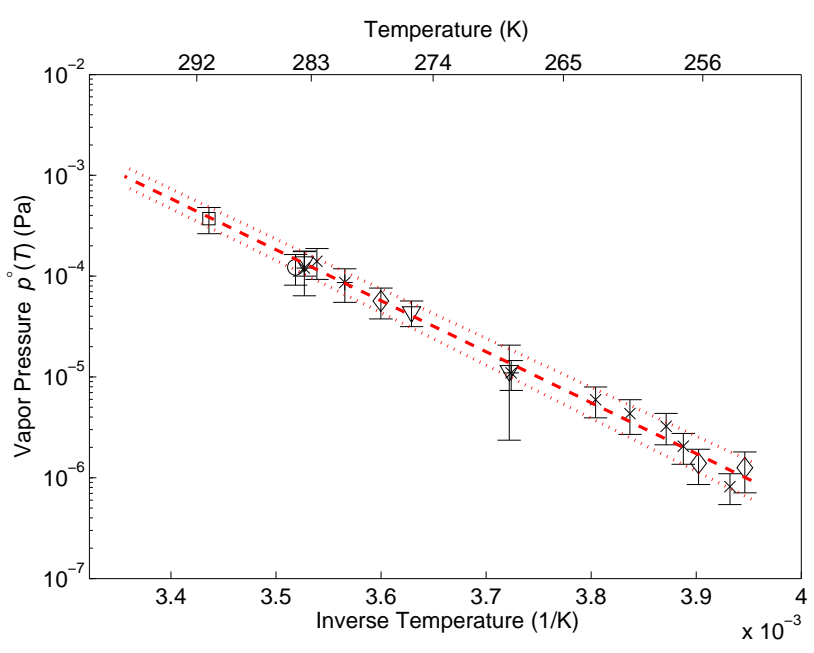

Fig. 5. Pure component vapor pressure $p^{\circ, \mathrm{L}}$ of 2-methylglutaric acid (open symbols, denoting six different particles). Fit line (dashed) is to Eq. (5) with $2 \sigma$ error bounds shown as dotted lines. These data demonstrate that this method produces consistent, high quality data over a broad range of pressures.

the results of Booth et al. (2010) for tartaric acid. However, comparison to measurements of other stereoisomers are also reasonable, as all are expected to have a similar vapor pressure and the six order of magnitude discrepancy lies outside the expected range of variance due to stereoisomerism.

\subsection{Citric acid}

The $p^{\circ, \mathrm{L}}$ measured for CA, shown in Fig. 7, were both indistinguishable from zero. Measurement times were 4 days ( $311 \mathrm{~K})$ and $\sim 12$ days $(\sim 308 \mathrm{~K})$, not including instrument settling time. The measurement at $311 \mathrm{~K},<1.6 \times 10^{-7} \mathrm{~Pa}$, is a crude upper bound that is also valid at $T^{\ominus}$. However, following the logic employed for TA, we extrapolate from this point to $T^{\ominus}$, again using $\Delta H_{\text {vap }}^{\ominus}$ of 75 and $250 \mathrm{~kJ} \mathrm{~mol}^{-1}$. The two upper limits from this extrapolation are $<4.0 \times 10^{-8} \mathrm{~Pa}$ for $75 \mathrm{~kJ} \mathrm{~mol}^{-1}$ and $<1.4 \times 10^{-9} \mathrm{~Pa}$ for $250 \mathrm{~kJ} \mathrm{~mol}^{-1}$. All three of these upper limits are at least four orders of magnitude below the value reported by Booth et al. (2010).

We also compare our measurement with measurements made above the melting point of $\mathrm{CA}(T>426 \mathrm{~K}$, Yaws et al., 2009). Using Eq. (5), $\Delta H_{\text {vap }}=146 \mathrm{~kJ} \mathrm{~mol}^{-1}$ was extracted by fitting the lowest $25 \mathrm{~K}$ of the parameterization. Assuming a $10 \%$ error on this $\Delta H_{\text {vap }}$ and extrapolating from the lower point of validity in the parameterization $(T=426 \mathrm{~K}$, $p=0.34 \mathrm{~Pa}$ ), we calculate $p^{\circ, \mathrm{L}}$ at $T^{\ominus}$ is in the range (140) $\times 10^{-9} \mathrm{~Pa}$, consistent with our upper limits. 


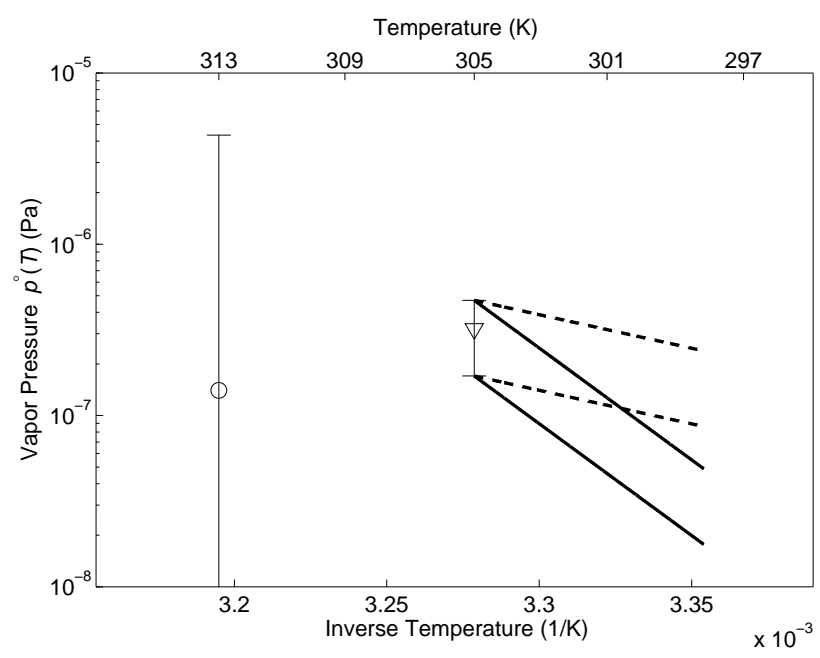

Fig. 6. Pure component vapor pressure $p^{\circ, \mathrm{L}}$ of DL-tartaric acid (open symbols, denoting two different particles). The measurement at $\sim 312 \mathrm{~K}$ is indistinguishable from zero. The upper and lower limit of vapor pressure at $T \approx 305 \mathrm{~K}$ is extrapolated to $T^{\ominus}$ using $\Delta H_{\text {vap }}^{\ominus}$ of 75 (dashed) or 250 (solid) $\mathrm{kJ} \mathrm{mol}^{-1}$ and Eq. (5). The largest possible range of vapor pressure at $T^{\ominus}$ from this extrapolation is reported.

\subsection{Comparison to empirical models of vapor pressure}

The EVAPORATION model described in Compernolle et al. (2011) was run both with and without the empirical correction term (Eq. 31 of Compernolle et al., 2011) to $p^{\circ, \mathrm{L}}$ for functionalized polyacids. For 2-mMA and 2-mGA, the correction terms do not apply and both model outputs are identical. The model has a mean absolute deviation of 0.4 orders of magnitude for polyacids (Compernolle et al., 2011), which we take as the uncertainty in model output. The results of these calculations are displayed in Fig. 2, along with the outputs of two other frequently-used vapor pressure estimations methods (Nannoolal et al., 2008; Moller et al., 2008) for comparison, both of which were calculated using the same estimated normal boiling points $T_{\mathrm{b}}$ (at a total pressure of $101.325 \mathrm{kPa}$ ) (Nannoolal et al., 2004) as inputs.

In the following analysis, we will focus on comparison to the EVAPORATION model as this model includes the empirical correction for substituted polyacids. The measurements of 2-mMA presented here are around a factor of two below the lower bound of model output, while 2-mGA is within the bounds of EVAPORATION model output. We view these agreements as reasonable, if not entirely satisfactory. In contrast, the substituted polyacids 2-hMA, TA, and CA have measured $p^{\circ, \mathrm{L}}$ that are a factor of $\sim 500(2$-hMA), three orders of magnitude (TA) and at least three orders of magnitude (CA) lower than the lower bound of the EVAPORATION model output, which includes the empirical correction term. Predictions from the EVAPORATION model without the empirical correction are consistent with (TA, CA) or

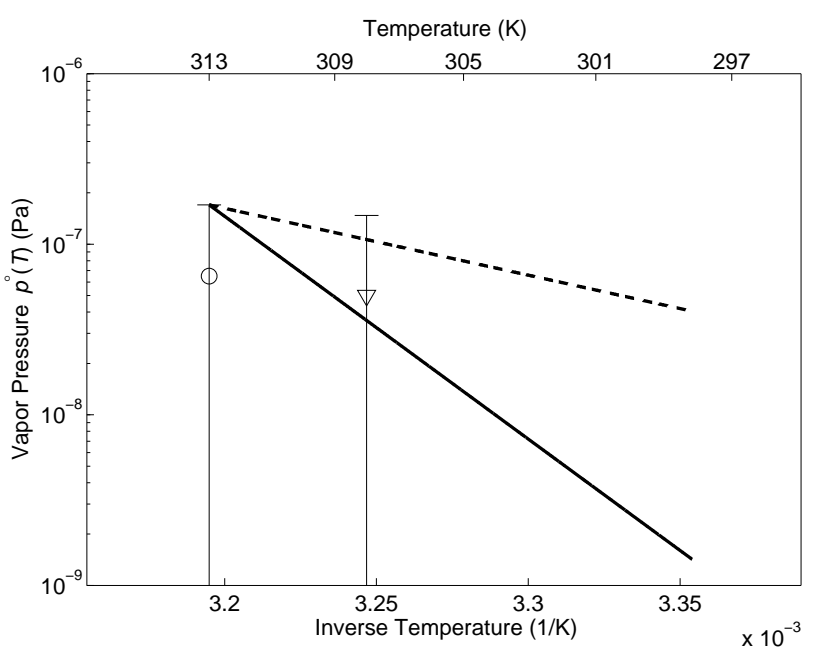

Fig. 7. Pure component vapor pressure $p^{\circ, \mathrm{L}}$ of citric acid (open symbols, denoting two different particles). Both measurements were indistinguishable from zero. The measured upper limit at $T \approx 311 \mathrm{~K}$ is extrapolated to yield the upper limit at $T^{\ominus}$ using $\Delta H_{\text {vap }}^{\ominus}$ of 75 (dashed) or 250 (solid) $\mathrm{kJ} \mathrm{mol}^{-1}$.

only one order of magnitude higher than (2-hMA) the EDBderived $p^{\circ, \mathrm{L}}$. Altogether, these measurements are more consistent with the EVAPORATION model output that does not use the empirical correction term for substituted polyacids.

\subsection{Comparison to solid-state results}

The disagreement between $p^{\circ, \mathrm{L}}\left(T^{\ominus}\right)$ for the compounds studied here and previous measurements is currently unexplained. As discussed in Soonsin et al. (2010), one possibility is that the physical state in other measurements was not fully controlled. This error would occur if some amorphous material was present in the KEMS apparatus of Booth et al. (2010), at which point the measurement reported as "solid" $\left(p^{\circ, \mathrm{S}}\left(T^{\ominus}\right)\right)$ might actually reflect the vapor pressure of amorphous liquid, namely $p^{\circ, \mathrm{L}}\left(T^{\ominus}\right)$. The hypothesis can be tested by comparing $p^{\circ, \mathrm{L}}\left(T^{\ominus}\right)$ and $p^{\circ, \mathrm{S}}\left(T^{\ominus}\right)$ from different measurement techniques.

Measurements of $p^{\circ, \mathrm{S}}$ for all compounds studied here are available, including direct measurement by KEMS (Booth et al., 2010), extrapolation from $T \approx 340 \mathrm{~K}$ using Knudsen mass-loss effusion (Ribeiro da Silva et al., 2000; Ribeiro da Silva et al., 2001), and extrapolation from $411 \mathrm{~K}<T<440$ $\mathrm{K}$ using a simultaneous torsion and mass-loss effusion technique (de Wit et al., 1983). These measurements are summarized in Table 4 and graphically depicted in Fig. 2. For 2-mMA and 2-mGA (which are in reasonable agreement with previous results), our $p^{\circ, \mathrm{L}}\left(T^{\ominus}\right)$ is larger than previously reported $p^{\circ, \mathrm{S}}\left(T^{\ominus}\right)$, as expected. A similar enhancement in $p^{\circ, \mathrm{L}}\left(T^{\ominus}\right)$ over $p^{\circ, \mathrm{S}}\left(T^{\ominus}\right)$ was calculated by Booth et al. (2010) for these two compounds, and the measurements of $p^{\circ, \mathrm{S}}\left(T^{\ominus}\right)$ of Booth et al. (2010) are in agreement with the 
measurements of Ribeiro da Silva et al. (2000) and Ribeiro da Silva et al. (2001). However, the $p^{\circ, \mathrm{S}}\left(T^{\ominus}\right)$ reported by Booth et al. (2010) for 2-hMA, CA, and TA are all at least one order of magnitude larger than the largest upper limit or value of $p^{\circ, \mathrm{L}}\left(T^{\ominus}\right)$ reported here. Thus, the physical state of the sample cannot be the only factor leading to the large differences between this work and previously reported values.

To the authors' knowledge, the only measurements of $p^{\circ, \mathrm{S}}\left(T^{\ominus}\right)$ for CA and 2-hMA are provided by Booth et al. (2010). However, measurements of meso-tartaric acid (a stereoisomer of tartaric acid that is expected to have similar physical properties to DL-tartaric acid) were made by de Wit et al. (1983) in the range $411 \mathrm{~K}<T<440 \mathrm{~K}$. Using the reported $\Delta H_{\text {sub }}$ of $156.9 \mathrm{~kJ} \mathrm{~mol}^{-1}$ in de Wit et al. (1983) and assuming $2 \%$ error on that value, extrapolation to $T=298.15 \mathrm{~K}$ using Eq. (5) yields $p^{\circ, \mathrm{S}}=(1.3-2.6) \times 10^{-9}$ $\mathrm{Pa}$ at $298.15 \mathrm{~K}$. This value is around 5 orders of magnitude smaller than the reported $p^{\circ, \mathrm{S}}\left(T^{\ominus}\right)$ for TA in Booth et al. (2010) and is consistent with (i.e., less than or equal to) the extrapolated $p^{\circ, \mathrm{L}}\left(T^{\ominus}\right)$ of Yaws et al. (2009).

\section{Implications}

\subsection{Partitioning of atmospheric aerosols}

The propensity of organic material to re-enter the gas phase after condensation to an aerosol is postulated to be a crucial control on further chemical processing (e.g., Salo et al., 2011). However, at some point a substance that has sufficiently low $p^{\circ, \mathrm{L}}$ is expected to remain in the condensed phase during the residence time of the particle in the atmosphere. Donahue et al. (2011) suggests that compounds with a $p^{\circ, \mathrm{L}}$ of $\sim 1.3 \times 10^{-6} \mathrm{~Pa}$ or lower will be "almost completely condensed under typical ambient conditions". The measurements of $p^{\circ, \mathrm{L}}\left(T^{\ominus}\right)$ for 2-hMA, CA and TA presented here are near or below this value, while other published values for the same compounds (see Table 4) are above the cutoff by a few orders of magnitude. Thus, the accurate determination of the $p^{\circ}, \mathrm{L}$ of these compounds will influence not only estimations of their partitioning between the gas and condensed phase, but also the mechanism by which they are further oxidized. This conclusion is not limited to 2-hMA, CA, and TA, but extends to all compounds that may have a $p^{\circ, \mathrm{L}}$ which is significantly over-estimated by current vapor pressure calculation techniques.

\subsection{Evaporation rates in laboratory measurements}

The time needed for a single-component particle to evaporatively shrink to $\frac{1}{e}$ of its original radius is

$\Delta t=\left(1-\frac{1}{e^{2}}\right) \times \frac{\left(r\left(t_{0}\right)\right)^{2} \rho R T}{2 D_{\mathrm{v}} p^{\circ} M}$,

where $\Delta t$ is the elapsed time, and other symbols are defined as above (Davis and Ray, 1977). Using the $D_{\mathrm{v}}$ given in Ta- ble 3 , the e-folding evaporation times for a $10 \mu \mathrm{m}$ radius particle of pure TA at $T^{\ominus}$ is $8.3 \mathrm{~min}$ for $p^{\circ, \mathrm{L}}=0.31 \mathrm{~Pa}$ (Booth et al., 2010) and $\sim 15 \mathrm{yr}$ for $p^{\circ, \mathrm{L}}=3.2 \times 10^{-7} \mathrm{~Pa}$ (this work) (details and calculation given in Appendix D). Similarly for CA, the e-folding evaporation time would be $10.9 \mathrm{~h}$ for $p^{\circ, \mathrm{L}}=3.1 \times 10^{-3} \mathrm{~Pa}$ (Booth et al., 2010) and $\sim 23 \mathrm{yr}$ for $p^{\circ, \mathrm{L}}=1.6 \times 10^{-7} \mathrm{~Pa}$ (this work). Thus, the fast evaporation times associated with the measurements of Booth et al. (2010) are not compatible with these EDB observations, which did not show any discernible evaporation of CA for several days even at $\sim 310 \mathrm{~K}$.

For particles of radius $100 \mathrm{~nm}$ (similar to those used in TDMA experiments), the e-folding evaporation times would be four orders of magnitude smaller, roughly $50 \mathrm{~ms}$ and $14 \mathrm{~h}$ for the two $p^{\circ, \mathrm{L}}$ for TA given above. Such a large difference should be easy to observe in a TDMA and we suggest that measurements of these and other compounds on such an instrument could be used to corroborate our results.

\section{Conclusions}

Measurements of the pure component liquid vapor pressure $\left(p^{\circ, \mathrm{L}}\right)$ of several substituted polycarboxylic acids were made by tracking the decreasing size of an evaporating particle in an EDB. As the measurements in the current study were taken on a solution already in the liquid state or on the pure subcooled melt, they preclude the possibility of error introduced via the conversion from solid-state to liquid-state vapor pressure.

Our measurements $p^{\circ, \mathrm{L}}\left(T^{\ominus}\right)$ agree reasonably well with previous measurements of 2-methylmalonic and 2methylglutaric acids, and with an extrapolation of measurements taken above the melting point of citric acid $(T>$ $426 \mathrm{~K})$, but are at least a factor of 500 lower than the only other measurements of 2-hydroxymalonic, tartaric, and citric acids performed near room temperature by Booth et al. (2010). The discrepancy between our measurements and previous studies may be partially explained by the presence of liquid or amorphous semi-solid inclusions in a bulk sample that was assumed to be crystalline, but the disagreement among the vapor pressures of some of the polyacids is so large that there is no obvious solution that brings these EDB measurements and the KEMS measurements of Booth et al. (2010) into agreement.

The substantial disagreement between these two techniques shows that measurements of the vapor pressure of substituted polyacids should be revisited. The agreement for the methyl-substituted polyacids 2-mMA and 2-hMA shows that these two techniques can provide consistent results. Indeed, the measurements of unsubstituted oxalic, succinic, and glutaric acids made by Soonsin et al. (2010) using this same EDB apparatus and technique are all consistent with the $p^{\circ, \mathrm{L}}\left(T^{\ominus}\right)$ reported by Booth et al. (2010) for those compounds. 
The measurements presented here are more consistent with the EVAPORATION model which excludes the empirical correction of polyacids. Perhaps coincidentally, the methyl-substituted polyacids for which agreement with other methods was found did not require an empirical correction term in the EVAPORATION model, while 2-hMA, CA and TA did. Altogether, these data suggest that the discrepancy between the EDB and KEMS technique (and by extension, the EVAPORATION model, which includes the empirical polyacid correction) arises in polyacids with oxygen-bearing (or at least non-aliphatic) substituent groups. This suggests very strongly that for the time being, the EVAPORATION model should be used without the empirical correction for substituted polyacids.

\section{Appendix A}

\section{Examples of radius data}

Examples of the raw radius data as a function of time for 2-mGA, TA, and CA are shown in Fig. A1. Each experimental trace starts after the particle is equilibrated with respect to RH and $T$, and shows a very small but discernible shrinking of the particle over the course of many days. These signals correspond to vapor pressures of (a) $1.1 \times 10^{-6} \mathrm{~Pa}$, (b) $3.6 \times 10^{-7} \mathrm{~Pa}$, and (c) $<1.6 \times 10^{-7} \mathrm{~Pa}$. Measurements of 2-mMA, Fig. A1a, were easily above limit of quantitation, as evidenced by the observable evaporation even at reduced temperature. The measurement of TA, Fig. A1b, is approaching the limit of quantitation, as instrumental noise is visibly overlaid with evaporative shrinking. Finally, measurements of CA, Fig. A1c, are below limit of quantitation. The $\sim 10$ day experiment shown here shows a quasi-exponential profile that is typical of, e.g., the loss of residual water from the particle and not of slow evaporative loss of CA. In this case, the assumption that the particle is in equilibrium with its surroundings (i.e., that $a_{\mathrm{w}}=\mathrm{RH}$ ) is violated. The error analysis procedure described in Appendix B correctly yields a vapor pressure indistinguishable from zero without any manual intervention. However, we can still place an upper limit on the vapor pressure of CA by observing that its evaporation is small enough to be masked by these very small shrinking rates due to evaporation of traces of water ( $2 \mathrm{~nm}$ in 7 days).

\section{Appendix B}

\section{Error analysis}

\section{B1 Statistical error}

Standard error propagation was used to calculate the statistical error in $p^{\circ, \mathrm{L}}\left(T^{\ominus}\right)$ derived from experiments at multiple $T$ and RH. In general, the statistical error on a measurement depends on the duration of the measurement, the $\mathrm{RH}$ of the
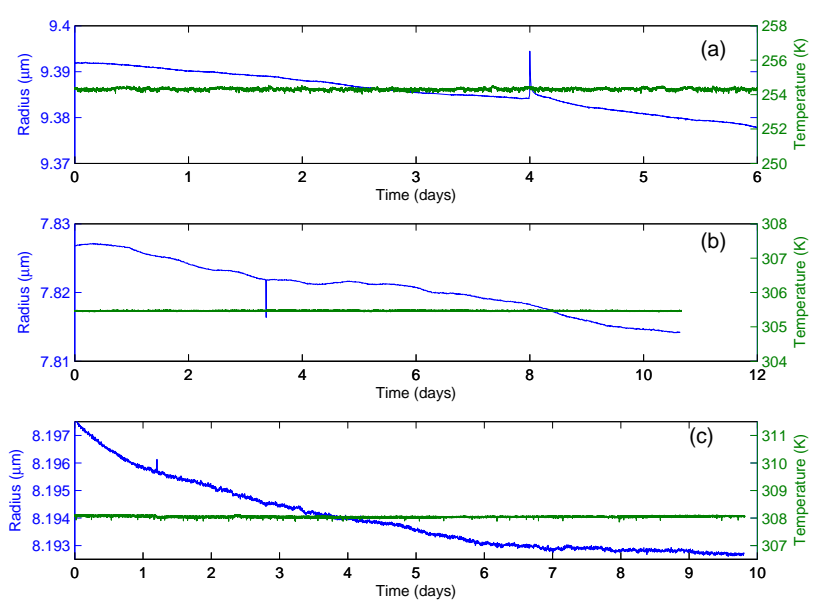

Fig. A1. Radius data from (a) 2-methylglutaric acid, (b) DL-tartaric acid and (c) citric acid. Note that (a) and (b) have coarse radius range (30 and $20 \mathrm{~nm}$, respectively) while (c) has a range of $5 \mathrm{~nm}$. The spike in panel (a) near day four is an instrumental artifact and was excluded from the fit of $\frac{\mathrm{d} r^{2}}{\mathrm{~d} t}$. Panel (c) appears to show an exponential decrease that is consistent with an exceedingly slow loss of water. The evaporative loss of citric acid in panel (c) must be lower than the loss rate of water after 10 days of drying at $35^{\circ} \mathrm{C}$.

measurement, and the steepness of the hygroscopic growth factor that is unique to each compound. For LVOC, the calculated error is dominated by the particle response to slight changes in $\mathrm{RH}$, while experimental uncertainties for materials with higher $p^{\circ, \mathrm{L}}$ depend primarily on the accuracy of the retrieval of the absolute radius.

The assumed statistical errors in the variables of Eq. (1) are estimated as follows:

- Radius, the larger of (i) $10 \%$, based on the retrieval of $r\left(t_{0}\right)$ from the angular scattering pattern, or (ii) the error due to variations in $r$ due to small changes in RH (cf., Sect. B2).

- Mole fraction, $2 \%$, based on the variation of AIOMFAC outputs with respect to the temperature range of the measurements and response of $x$ to small changes in RH.

- Density, $5 \%$, a conservative estimate due to the extrapolation from bulk measurements.

- Temperature, $0.25 \mathrm{~K}$, the maximum allowed variation in temperature over one experimental measurement

- Diffusivity of vapor, $20 \%$, following the suggested value of Krieger et al. (2012).

\section{B2 Error arising from response of particles to changes in $\mathbf{R H}$}

In addition to the standard statistical uncertainty expected in a measurement, a potential error exists due to the response 
of the particle to fluctuations in RH. In this case, the measurement of Mie resonance wavelength (and thus the change in particle radius) is highly accurate but the assumption that evaporation is the only process causing the particle to change size (at constant $T$ and $\mathrm{RH}$ within instrumental stability) may be incorrect, leading to a confounding error in $\frac{\mathrm{d} r}{\mathrm{~d} t}$. Thus, while our ability to measure $\frac{\mathrm{d} r}{\mathrm{~d} t}$ is excellent, the error in $\frac{\mathrm{d} r}{\mathrm{~d} t}$ was increased for the purpose of error propagation as follows. The measurement technique described here assumes that the change in particle size is only due to evaporation of organic molecules and an associated amount of water molecules, i.e., that the particle is equilibrated with its environment in $T$ and especially with respect to water vapor. Thus, a particle shrinking due to decreasing $\mathrm{RH}$ might be interpreted to have high $p$, while a particle growing due to increasing RH might display an artificially slow decrease in radius. Fits to data were made such that measured $\Delta \mathrm{RH}<$ $0.5 \%$ and $\Delta T<0.25 \mathrm{~K}$ over the course of the measurement. We estimate that the ability of our RH sensor to detect drifts in measured $\mathrm{RH}$ is at worst $0.5 \%$, meaning that a drift of $0.5 \%$ actual $\mathrm{RH}$ could occur without registering a trend in measured RH.

Calculation of the false signal resulting from these small variations in $\mathrm{RH}$ requires a knowledge of the response of the particle to changes in $\mathrm{RH}$, which is highly non-linear. Above $100 \% \mathrm{RH}$, the particle grows without bound, and at high $\mathrm{RH}$ the particle is extremely sensitive to small variations in $\mathrm{RH}$, while under low RH conditions the growth is relatively small. For this analysis, the AIOMFAC model results were inverted to produce a growth factor:

$\mathrm{GF}=\frac{V_{\text {org }}+\left(\frac{1}{x}-1\right) \times V_{\mathrm{w}}}{V_{\text {org }}}$.

The growth factor GF is normalized to be unity at $x=1$ (pure organic component) and is generated by assuming that the number of moles of organic compound are conserved during hygroscopic growth and that partial molar volumes are additive. Each measurement occurs at a specific $\mathrm{RH}$, which defines a range of growth factors depending on the steepness of GF at that point. The error is then derived by assuming a totally non-volatile particle and calculating the largest possible positive and negative changes in radius from the starting $\mathrm{RH}$ plus or minus the tolerance of $0.5 \% \mathrm{RH}$. For substances with higher vapor pressures such as 2-mMA, this error plays a minor role in the calculation of the total statistical error, while for very short experiments (small $\mathrm{d} t$ ) or very low $p$ measurements (small true $\mathrm{d} r$ ), this term becomes dominant.

\section{B3 Systematic errors}

As the $p$ calculated in Eq. (1) depends on the square of the absolute particle radius, a systematic error is possible due to error in the determination of $r\left(t_{0}\right)$. This error would be apparent only when comparing several particles of the same material, as each particle is self-consistent with respect to initial radius. Such an error would appear as a set of data from one particle that is increased or decreased in $p^{\circ}(T)$ by a constant factor. Based on the six particles shown in Fig. 5, we do not observe any systematic shifting of the data from one particle away from the others. Thus, the systematic error in the determination of $r\left(t_{0}\right)$ is smaller than the statistical error and can be neglected.

Another systematic error that is very difficult to evaluate arises from the gas-phase diffusivity $\left(D_{\mathrm{v}}\right)$ of the organic compound (see discussion in Krieger et al., 2012). The $p$ in Eq. (1) is inversely proportional to gas-phase organic diffusivity, which is calculated based on two estimated parameters (as detailed in Sect. 2.4). Unlike the potential error in $r\left(t_{0}\right)$, we have no ability to isolate the influence of systematic error in $D_{\mathrm{v}}$ as all experiments with the same material used the same parameterization. In a future comparison to these results, the influence of any systematic error in $D_{\mathrm{v}}$ can be minimized by taking into account the actual values that were used (given in Table 3).

\section{Appendix C}

\section{Miscellaneous effects}

Here we present a justification for neglecting the influence of the Kelvin effect and the reduction in vapor pressure of polarizable species in a charged droplet, and for neglecting the influence of dimerization on the gas-phase diffusivity of the organic component.

\section{C1 Influence of droplet size and charge}

The Kelvin effect, the enhancement of vapor pressure over a curved surface, is well known and must be considered as part of aerosol growth or evaporation in small particles. In addition to the Kelvin effect, recent work by Nielsen et al. (2011) showed that the near-surface partial pressure of water vapor or other gasses with a permanent dipole or high polarizability is increased above a charged particle. Using the formalism of Lapshin et al. (2002), Eq. (11) expressed in SI units is

$$
\begin{gathered}
\ln \frac{p}{p_{0}}=\frac{2 \sigma v}{k r T}-\frac{\mu_{\mathrm{D}} Q}{4 \pi \epsilon_{0} k T r^{2}} \times L\left(\frac{\mu_{\mathrm{D}} Q}{4 \pi \epsilon_{0} k T r^{2}}\right) \\
-\frac{v Q^{2}}{32 \pi^{2} \epsilon_{0} k T r^{4}}\left(1-\frac{1}{\epsilon_{\mathrm{L}}}\right),
\end{gathered}
$$

where $L$ is the Langevin function $L(x)=\operatorname{coth}(x)-1 / x$ and all symbols are defined as in Lapshin et al. (2002) except radius $r$, which has been changed from $R$ to avoid confusion with the gas constant. Using the values in Table $C 1$, the value of $p / p_{0}$ was calculated as 1.0004 , a predicted enhancement of $0.04 \%$ in the vapor pressure. Thus, the combined Kelvin effect and charge stabilization effect are minor compared to 
Table C1. Definitions and values for parameters in Eq. (C1).

\begin{tabular}{llll}
\hline Variable & Description & Value & Unit \\
\hline$\sigma$ & Surface tension & $7.2 \times 10^{-2}$ & $\mathrm{~N} \mathrm{~m}^{-1}$ \\
$v$ & Molecular volume & $2.99 \times 10^{-29}$ & $\mathrm{~m}^{3}$ molecules $^{-1}$ \\
$\epsilon_{0}$ & Vacuum permittivity & $8.85 \times 10^{-12}$ & $\mathrm{~m}^{-3} \mathrm{~kg}^{-1} \mathrm{~s}^{4} \mathrm{~A}^{2}$ \\
$k$ & Boltzmann constant & $1.38 \times 10^{-23}$ & $\mathrm{~J} \mathrm{~K}^{-1}$ \\
$T$ & Temperature & 298 & $\mathrm{~K}$ \\
$r$ & Particle radius & $2.5 \times 10^{-6}$ & $\mathrm{~m}$ \\
$\mu_{\mathrm{D}}$ & Dipole moment & $5.99 \times 10^{-30}$ & $\mathrm{Cm}$ \\
$Q$ & Charge & $1.6 \times 10^{-15}$ & $\mathrm{C}$ \\
$\epsilon_{\mathrm{L}}$ & Static relative permittivity & 80 & unitless \\
\hline
\end{tabular}

experimental error and are not expected to influence our results.

\section{C2 Dimerization of gas-phase organics}

An additional consideration in estimating the organic vaporphase diffusivity in these materials is the possibility of carboxylic acid dimer formation. Dimerization of carboxylic acids is well known, especially in the case of smaller molecules such as, e.g., formic acid; dicarboxylic acid dimers have been studied in the context of new particle nucleation (see, e.g., Hallquist et al., 2009, and references therein). Substantial dimerization would result in reduced gas-phase diffusivity and would influence the apparent vapor pressure of the organic (and the monomer) vapor pressure. However, dimerization of the vapor is unlikely to influence the measurements due to the low gas-phase concentration of the organic component in the experimental apparatus. For a droplet in thermodynamic equilibrium, the vapor pressure specifies the partial pressure of that material in the vapor phase in the diffusionlimited region nearest the droplet. Thus, the mixing ratio of organic vapor (partial pressure of order $1 \times 10^{-3} \mathrm{~Pa}$ or less) in an atmosphere of $\sim 80 \times 10^{3} \mathrm{~Pa}$ continuously flowing organic-free $\mathrm{N}_{2}$ would be of order $1 \times 10^{-8}$ or lower. Assuming that di- and mono-carboxylic acids have similar dimerization properties (the dissociation constants for monocarboxylic acids in the gas phase are large, e.g., formic acid, $3.6 \times 10^{2} \mathrm{~Pa}$ at $296 \mathrm{~K}$, Vander Auwera et al., 2007), that the effect of chain length on enthalpy of dimerization is minimal (cf., Eq. 7 of Tsonopoulos and Prausnitz, 1970) and solving the quadratic equation as described in, e.g., Zuend et al. (2011), the fraction of molecules dimerized would be $\sim 1$ per $1 \times 10^{8}$ for a sample with $p^{\circ, \mathrm{L}}\left(T^{\ominus}\right) \sim 1 \times 10^{-6} \mathrm{~Pa}$. Even at the highest vapor pressures observed in this study of $\sim 1 \times 10^{-3} \mathrm{~Pa}$, less than 1 molecule in $1 \times 10^{5}$ is predicted to be dimerized. Thus, dimerization is unlikely to play a major role in these experiments.
Table D1. Definitions and values for parameters in Eq. (D2).

\begin{tabular}{llll}
\hline Variable & Description & Value & Unit \\
\hline$r\left(t_{0}\right)$ & Initial particle radius & $1 \times 10^{-5}$ & $\mathrm{~m}$ \\
$\rho$ & Density & 1.749 & $\mathrm{~g} \mathrm{~cm}^{-3}$ \\
$R$ & Gas constant & 8.314 & $\mathrm{~J} \mathrm{~mol}^{-1} \mathrm{~K}^{-1}$ \\
$T$ & Temperature & 298.15 & $\mathrm{~K}$ \\
$D_{\mathrm{v}}$ & Gas phase diffusivity of organic & 0.08 & $\mathrm{~cm}^{2} \mathrm{~s}^{-1}$ \\
$p^{\circ}$ & Vapor pressure & 0.31 & $\mathrm{~Pa}$ \\
$M$ & Molar mass & 150.08 & $\mathrm{~g} \mathrm{~mol}^{-1}$ \\
\hline
\end{tabular}

\section{Appendix D}

\section{Evaporation times sample calculation}

Beginning with Davis and Ray (1977), Eq. (3), and substituting $r$ for $a$ to maintain consistency with our earlier nomenclature,

$r^{2}(t)=r^{2}\left(t_{0}\right)+S_{12} \times\left(t-t_{0}\right)$.

Now let $\Delta t \equiv\left(t-t_{0}\right)$ and let $r(t)=\frac{1}{e} \times r\left(t_{0}\right)$ to find the efolding evaporation time for a pure particle. Then

$$
\begin{aligned}
& \frac{1}{e^{2}} r^{2}\left(t_{0}\right)=r^{2}\left(t_{0}\right)+S_{12} \times \Delta t \\
& \left(1-\frac{1}{e^{2}}\right) r^{2}\left(t_{0}\right)=-S_{12} \times \Delta t .
\end{aligned}
$$

Now $S_{12} \equiv \frac{-2 D_{\mathrm{v}} p^{\circ} M}{\rho R T}$ so that

$\Delta t=\left(1-\frac{1}{e^{2}}\right) \frac{r^{2}\left(t_{0}\right) \rho R T}{2 D_{\mathrm{v}} p^{\circ} M}$.

Using the values in Table D1 for TA,

$\Delta t=\left(1-\frac{1}{e^{2}}\right)$

$\frac{1 \times 10^{-10} \mathrm{~m}^{2} \times 1.749 \mathrm{~g} \mathrm{~cm}^{-3} \times 8.314 \mathrm{~J} \mathrm{~mol}^{-1} \mathrm{~K}^{-1} \times 298.15 \mathrm{~K}}{2 \times 0.08 \mathrm{~cm}^{2} \mathrm{~s}^{-1} \times 0.31 \mathrm{~Pa} \times 150.08 \mathrm{~g} \mathrm{~mol}^{-1}}$

$\Delta t=5.04 \times 10^{-8} \frac{\mathrm{m}^{5} \mathrm{~s}}{\mathrm{~cm}^{5}} \times\left(\frac{100 \mathrm{~cm}}{1 \mathrm{~m}}\right)^{5}=5.04 \times 10^{2} \mathrm{~s}=8.4 \mathrm{~min}$

and $\sim 15 \mathrm{yr}$ for $p^{\circ}=3.2 \times 10^{-7} \mathrm{~Pa}$. For CA, using $M=$ $192 \mathrm{~g} \mathrm{~mol}^{-1}$ and $p^{\circ}=3.1 \times 10^{-3} \mathrm{~Pa}$ or $1.6 \times 10^{-7} \mathrm{~Pa}$, we calculate $10.9 \mathrm{~h}$ and $\sim 23 \mathrm{yr}$, respectively. Due to the squared dependence on initial particle radius, changing from $10 \mu \mathrm{m}$ to $100 \mathrm{~nm}$ radius particle results in a four order of magnitude decrease in e-folding time. 
Table E1. List of symbols and abbreviations.

\begin{tabular}{lll}
\hline Symbol & Meaning & $\mathrm{SI} \mathrm{Unit}$ \\
\hline$\Delta H_{\text {vap }}^{\ominus}$ & Enthalpy of vaporization at $T^{\ominus}$ & $\mathrm{kJ} \mathrm{mol}^{-1}$ \\
$\lambda$ & Peak wavelength of a Mie resonance & $\mathrm{m}$ \\
$\rho$ & Density & $\mathrm{kg} \mathrm{m}^{-3}$ \\
$a$ & activity coefficient & - \\
$\mathrm{L} / \mathrm{SVOC}$ & low- and semi-volatile organic compound & - \\
$D_{\mathrm{V}}$ & Vapor phase diffusivity & $\mathrm{m}^{2} \mathrm{~s}^{-1}$ \\
$\mathrm{GF}$ & (radius) growth factor & - \\
EDB & Electrodynamic balance & - \\
KEMS & Knudsen effusion mass spectrometry & - \\
$M$ & Molar mass & $\mathrm{kg} \mathrm{mol}^{-1}$ \\
$p$ & Vapor pressure & $\mathrm{Pa}$ \\
$p^{\mathrm{L}}$ & $p$ of liquid state sample & $\mathrm{Pa}$ \\
$p^{\circ}$ & Pure component vapor pressure in unspecified physical state & $\mathrm{Pa}$ \\
$p^{\circ}\left(T^{\ominus}\right)$ & $p^{\circ}$ at $T^{\ominus}$ & $\mathrm{Pa}$ \\
$p^{\circ, \mathrm{L}}$ & $p^{\circ}$ of liquid state sample & $\mathrm{Pa}$ \\
$p^{\circ, \mathrm{S}}$ & $p^{\circ}$ of solid state sample & $\mathrm{Pa}$ \\
$r$ & particle radius & $\mathrm{m}$ \\
$\mathrm{RH}$ & Relative humidity & - \\
$T$ & Temperature & $\mathrm{K}$ \\
$T^{\ominus}$ & Reference temperature, here 298.15 K & $\mathrm{K}$ \\
TDMA & Tandem differential mobility analyzer & - \\
$V$ & Molar volume & $\mathrm{m} \mathrm{mol}^{-1}$ \\
$x$ & mole fraction of the organic component & - \\
\hline & & \\
\hline & & \\
\hline
\end{tabular}

Acknowledgements. This material is based upon work supported by the United States National Science Foundation under award no. IRFP 1006117, by ETH Zürich, and by the Competence Center Environment and Sustainability of the ETH Domain (CCES) project IMBALANCE and OPTIWARES. Any opinions, findings, and conclusions or recommendations expressed in this material are those of the authors and do not necessarily reflect the views of the US National Science Foundation. Figure 2 was produced using the bar2.m code written by Mike Sheppard of the MIT Lincoln Laboratory. The authors thank Daniel Lienhard of ETH Zürich for performing measurements of the density of 2-methylglutaric acid.

Edited by: M. Petters

\section{References}

ACD/Labs: Advanced Chemistry Development (ACD/Labs) Software V11.02 (C 1994-2012 ACD/Labs), Retrieved from http: //www.cas.org/products/scifinder, 15 November, 2012.

Armbruster, D. and Pry, T.: Limit of blank, limit of detection and limit of quantitation., Clin Biochem Rev, 29 Suppl. 1, S49-52, http://www.ncbi.nlm.nih.gov/pubmed/18852857/, 2008.

Barley, M. H. and McFiggans, G.: The critical assessment of vapour pressure estimation methods for use in modelling the formation of atmospheric organic aerosol, Atmos. Chem. Phys., 10, 749767, doi:10.5194/acp-10-749-2010, 2010.

Bilde, M., Svenningsson, B., Mønster, J., and Rosenørn, T.: EvenOdd Alternation of Evaporation Rates and Vapor Pressures of
C3-C9 Dicarboxylic Acid Aerosols, Environ. Sci. Technol., 37, 1371-1378, doi:10.1021/es0201810, 2003.

Bird, R. B., Stewart, W. E., and Lightfoot, E. N.: Transport Phenomena, Wiley \& Sons, 2007.

Booth, A. M., Barley, M. H., Topping, D. O., McFiggans, G., Garforth, A., and Percival, C. J.: Solid state and sub-cooled liquid vapour pressures of substituted dicarboxylic acids using Knudsen Effusion Mass Spectrometry (KEMS) and Differential Scanning Calorimetry, Atmos. Chem. Phys., 10, 4879-4892, doi:10.5194/acp-10-4879-2010, 2010.

Bruns, E. A., Greaves, J., and Finlayson-Pitts, B. J.: Measurement of Vapor Pressures and Heats of Sublimation of Dicarboxylic Acids Using Atmospheric Solids Analysis Probe Mass Spectrometry, J. Phys. Chem. A, 116, 5900-5909, doi:10.1021/jp210021f, 2012.

Cappa, C. D., Lovejoy, E. R., and Ravishankara, A. R.: Determination of Evaporation Rates and Vapor Pressures of Very Low Volatility Compounds: A Study of the C4-C10 and C12 Dicarboxylic Acids, J. Phys. Chem. A, 111, 3099-3109, doi:10.1021/jp068686q, 2007.

Chattopadhyay, S. and Ziemann, P. J.: Vapor Pressures of Substituted and Unsubstituted Monocarboxylic and Dicarboxylic Acids Measured Using an Improved Thermal Desorption Particle Beam Mass Spectrometry Method, Aerosol Sci. Technol., 39, 10851100, doi:10.1080/02786820500421547, 2005.

Compernolle, S., Ceulemans, K., and Müller, J.-F.: EVAPORATION: a new vapour pressure estimation methodfor organic molecules including non-additivity and intramolecular interactions, Atmos. Chem. Phys., 11, 9431-9450, doi:10.5194/acp-119431-2011, 2011. 
Davis, E. J. and Ray, A. K.: Determination of diffusion coefficients by submicron droplet evaporation, J. Chem. Phys., 67, 414, doi:10.1063/1.434903, 1977.

de Wit, H. G. M., Bouwstra, J. A., Blok, J. G., and de Kruif, C. G.: Vapor pressures and lattice energies of oxalic acid, mesotartaric acid, phloroglucinol, myoinositol, and their hydrates, J. Chem. Phys., 78, 1470-1475, doi:10.1063/1.444836, 1983.

Donahue, N. M., Epstein, S. A., Pandis, S. N., and Robinson, A. L.: A two-dimensional volatility basis set: 1. organic-aerosol mixing thermodynamics, Atmos. Chem. Phys., 11, 3303-3318, doi:10.5194/acp-11-3303-2011, 2011.

Glantschnig, W. J. and Chen, S.-H.: Light scattering from water droplets in the geometrical optics approximation, Appl. Opt., 20, 2499-2509, doi:10.1364/AO.20.002499, 1981.

Hallquist, M., Wenger, J. C., Baltensperger, U., Rudich, Y., Simpson, D., Claeys, M., Dommen, J., Donahue, N. M., George, C., Goldstein, A. H., Hamilton, J. F., Herrmann, H., Hoffmann, T., Iinuma, Y., Jang, M., Jenkin, M. E., Jimenez, J. L., Kiendler-Scharr, A., Maenhaut, W., McFiggans, G., Mentel, Th. F., Monod, A., Prévôt, A. S. H., Seinfeld, J. H., Surratt, J. D., Szmigielski, R., and Wildt, J.: The formation, properties and impact of secondary organic aerosol: current and emerging issues, Atmos. Chem. Phys., 9, 5155-5236, doi:10.5194/acp-9-51552009, 2009.

Krieger, U. K., Marcolli, C., and Reid, J. P.: Exploring the complexity of aerosol particle properties and processes using single particle techniques, Chem. Soc. Rev., 41, 6631-6662, doi:10.1039/C2CS35082C, 2012.

Laguerie, C., Aubry, M., and Couderc, J. P.: Some physicochemical data on monohydrate citric acid solutions in water: solubility, density, viscosity, diffusivity, $\mathrm{pH}$ of standard solution, and refractive index, J. Chem. Eng. Data, 21, 85-87, doi:10.1021/je60068a031, 1976.

Lapshin, V., Yablokov, M. Y., and Palei, A. A.: Vapor Pressure over a Charged Drop, Russ. J. Phys. Chem., 76, 1901-1903, 2002.

Letcher, T. M. and Naicker, P. K.: Determination of vapor pressures using gas chromatography, J. Chromatogr. A, 1037, 107-114, doi:10.1016/S0021-9673(03)01299-8, 2004.

Lydersen, A. L.: Estimation of Critical Properties of Organic Compounds by the Method of Group Contributions, Tech. rep., Chemical Engineering Department, University of Wisconsin, 1955.

Lyons, L.: Statistics for Nuclear and Particle Physicists, Press Syndicate of the University of Cambridge, Cambridge CB2 1RP, UK, ISBN 052137934 2, 1986.

Moller, B., Rarey, J., and Ramjugernath, D.: Estimation of the vapour pressure of non-electrolyte organic compounds via group contributions and group interactions, Journal of Molecular Liquids, 143, 52-63, doi:10.1016/j.molliq.2008.04.020, 2008.

Mønster, J., Rosenørn, T., Svenningsson, B., and Bilde, M.: Evaporation of methyl- and dimethyl-substituted malonic, succinic, glutaric and adipic acid particles at ambient temperatures, J. Aerosol Sci., 35, 1453-1465, doi:10.1016/j.jaerosci.2004.07.004, 2004.

Nannoolal, Y., Rarey, J., Ramjugernath, D., and Cordes, W.: Estimation of pure component properties: Part 1. Estimation of the normal boiling point of non-electrolyte organic compounds via group contributions and group interactions, Fluid Phase Equilibria, 226, 45-63, doi:10.1016/j.fluid.2004.09.001, 2004.
Nannoolal, Y., Rarey, J., and Ramjugernath, D.: Estimation of pure component properties: Part 3. Estimation of the vapor pressure of non-electrolyte organic compounds via group contributions and group interactions, Fluid Phase Equilib., 269, 117-133, doi:10.1016/j.fluid.2008.04.020, 2008.

Nielsen, J. K., Maus, C., Rzesanke, D., and Leisner, T.: Charge induced stability of water droplets in subsaturated environment, Atmos. Chem. Phys., 11, 2031-2037, doi:10.5194/acp-11-20312011, 2011.

Pankow, J. F.: An absorption model of the gas/aerosol partitioning involved in the formation of secondary organic aerosol, Atmos. Environ., 28, 189-193, doi:10.1016/1352-2310(94)900949, 1994

Pankow, J. F.: Gas/particle partitioning of neutral and ionizing compounds to single and multi-phase aerosol particles. 1. Unified modeling framework, Atmos. Environ., 37, 3323-3333, doi:10.1016/S1352-2310(03)00346-7, 2003.

Pope, F. D., Tong, H.-J., Dennis-Smither, B. J., Griffiths, P. T., Clegg, S. L., Reid, J. P., and Cox, R. A.: Studies of Single Aerosol Particles Containing Malonic Acid, Glutaric Acid, and Their Mixtures with Sodium Chloride. II. Liquid-State Vapor Pressures of the Acids, J. Phys. Chem. A, 114, 10156-10165, doi:10.1021/jp1052979, 2010.

Prausnitz, J., Lichtenthaler, R., and de Azevedo, E.: Molecular thermodynamics of fluid-phase equilibria, Prentice-Hall International Series in the Physical and Chemical Engineering Sciences, Prentice-Hall PTR, ISBN: 0139777458, 1999.

Ribeiro da Silva, M. A. V., Monte, M. J. S., and Ribeiro, J. R.: Standard Enthalpies, Entropies, and Gibbs Functions of Sublimation of Four Alkyl-Substituted Malonic Acids, J. Chem. Eng. Data, 45, 756-759, doi:10.1021/je000090n, 2000.

Ribeiro da Silva, M. A. V., Monte, M. J. S., and Ribeiro, J. R.: Thermodynamic study on the sublimation of succinic acid and of methyl- and dimethyl-substituted succinic and glutaric acids, J. Chem. Thermodyn., 33, 23-31, doi:10.1006/jcht.2000.0715, 2001.

Riipinen, I., Koponen, I. K., Frank, G. P., Hyvärinen, A.-P., Vanhanen, J., Lihavainen, H., Lehtinen, K. E. J., Bilde, M., and Kulmala, M.: Adipic and Malonic Acid Aqueous Solutions: Surface Tensions and Saturation Vapor Pressures, J. Phys. Chem. A, 111, 12995-13002, doi:10.1021/jp073731v, 2007.

Salo, K., Jonsson, A. M., Andersson, P. U., and Hallquist, M.: Aerosol Volatility and Enthalpy of Sublimation of Carboxylic Acids, J. Phys. Chem. A, 114, 4586-4594, doi:10.1021/jp910105h, 2010.

Salo, K., Hallquist, M., Jonsson, Å. M., Saathoff, H., Naumann, K.H., Spindler, C., Tillmann, R., Fuchs, H., Bohn, B., Rubach, F., Mentel, Th. F., Müller, L., Reinnig, M., Hoffmann, T., and Donahue, N. M.: Volatility of secondary organic aerosol during $\mathrm{OH}$ radical induced ageing, Atmos. Chem. Phys., 11, 11055-11067, doi:10.5194/acp-11-11055-2011, 2011.

Soonsin, V., Zardini, A. A., Marcolli, C., Zuend, A., and Krieger, U. K.: The vapor pressures and activities of dicarboxylic acids reconsidered: the impact of the physical state of the aerosol, Atmos. Chem. Phys., 10, 11753-11767, doi:10.5194/acp-1011753-2010, 2010.

Tsonopoulos, C. and Prausnitz, J.: Fugacity coefficients in vaporphase mixtures of water and carboxylic acids, Chem. Eng. J., 1, 273-278, doi:10.1016/0300-9467(70)85014-6, 1970. 
Vander Auwera, J., Didriche, K., Perrin, A., and Keller, F.: Absolute line intensities for formic acid and dissociation constant of the dimer, J. Chem. Phys., 126, 124311, doi:10.1063/1.2712439, 2007.

Verevkin, S. P., Wandschneider, D., and Heintz, A.: Determination of Vaporization Enthalpies of Selected Linear and Branched C7, C8, C9, C11, and C12 Monoolefin Hydrocarbons from Transpiration and Correlation Gas-Chromatography Methods, J. Chem. Eng. Data, 45, 618-625, doi:10.1021/je990297k, 2000.

Washburn, E. W., West, C. J., and National Research Council (U.S.): International critical tables of numerical data, physics, chemistry and technology, vol. 1, McGraw-Hill, New York, 1926.

Yaws, C. L., Narasimhan, Prasad, K., and Gabbula, C.: Yaws' Handbook of Antoine Coefficients for Vapor Pressure (2nd Electronic Edition), http://www.knovel.com/web/portal/browse/ display?_EXT_KNOVEL_DISPLAY_bookid=1183 (retrieved January 2012), 2009.

Zardini, A. A., Krieger, U. K., and Marcolli, C.: White light Mie resonance spectroscopy used to measure very low vapor pressures of substances in aqueous solution aerosol particles, Opt. Express, 14, 6951-6962, doi:10.1364/OE.14.006951, 2006.

Zhang, S. and Davis, E. J.: Mass transfer from a single microdroplet to a gas flowing at low Reynolds Number, Chem. Eng. Commun., 50, 51-67, doi:10.1080/00986448708911815, 1987.
Zuend, A. and Seinfeld, J. H.: Modeling the gas-particle partitioning of secondary organic aerosol: the importance of liquidliquid phase separation, Atmos. Chem. Phys., 12, 3857-3882, doi:10.5194/acp-12-3857-2012, 2012.

Zuend, A., Marcolli, C., Luo, B. P., and Peter, T.: A thermodynamic model of mixed organic-inorganic aerosols to predict activity coefficients, Atmos. Chem. Phys., 8, 4559-4593, doi:10.5194/acp8-4559-2008, 2008.

Zuend, A., Marcolli, C., Peter, T., and Seinfeld, J. H.: Computation of liquid-liquid equilibria and phase stabilities: implications for RH-dependent gas/particle partitioning of organic-inorganic aerosols, Atmos. Chem. Phys., 10, 7795-7820, doi:10.5194/acp10-7795-2010, 2010.

Zuend, A., Marcolli, C., Booth, A. M., Lienhard, D. M., Soonsin, V., Krieger, U. K., Topping, D. O., McFiggans, G., Peter, T., and Seinfeld, J. H.: New and extended parameterization of the thermodynamic model AIOMFAC: calculation of activity coefficients for organic-inorganic mixtures containing carboxyl, hydroxyl, carbonyl, ether, ester, alkenyl, alkyl, and aromatic functional groups, Atmos. Chem. Phys., 11, 9155-9206, doi:10.5194/acp11-9155-2011, 2011. 